\title{
The 2020 national seismic hazard model for the United Kingdom
}

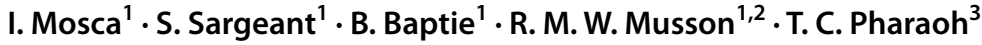

Received: 16 June 2021 / Accepted: 10 November 2021 / Published online: 8 January 2022

(c) British Geological Survey, UKRI 2021

\begin{abstract}
We present updated seismic hazard maps for the United Kingdom (UK) intended for use with the National Annex for the revised edition of Eurocode 8. The last national maps for the UK were produced by Musson and Sargeant (Eurocode 8 seismic hazard zoning maps for the UK. British Geological Survey Report CR/07/125, United Kingdom, 2007). The updated model uses an up-to-date earthquake catalogue for the British Isles, for which the completeness periods have been reassessed, and a modified source model. The hazard model also incorporates some advances in ground motion modelling since 2007, including host-to-target adjustments for the ground motion models selected in the logic tree. For the first time, the new maps are provided for not only peak ground acceleration (PGA) but also spectral acceleration at $0.2 \mathrm{~s}\left(\mathrm{SA}_{0.2 \mathrm{~s}}\right)$ and $1.0 \mathrm{~s}$ for $5 \%$ damping on rock (time-averaged shear wave velocity for the top $30 \mathrm{~m} \mathrm{Vs} 30 \geq 800 \mathrm{~m} / \mathrm{s}$ ) and four return periods, including 475 and 2475 years. The hazard in most of the UK is generally low and increases slightly in North Wales, the England-Wales border region, and western Scotland. A similar spatial variation is observed for PGA and $\mathrm{SA}_{0.2 \mathrm{~s}}$ but the effects are more pronounced for $\mathrm{SA}_{0.2 \mathrm{~s}}$. Hazard curves, uniform hazard spectra, and disaggregation analysis are calculated for selected sites. The new hazard maps are compared with the previous 2007 national maps and the 2013 European hazard maps (Woessner et al. in Bull Earthq Eng 13:3553-3596, 2015). There is a slight increase in PGA from the 2007 maps to this work; whereas the hazard in the updated maps is lower than indicated by the European maps.
\end{abstract}

Keywords Seismic hazard · United Kingdom · Earthquake catalogue · Seismic source model $\cdot$ Ground motion model

I. Mosca

imosca@bgs.ac.uk

1 British Geological Survey, The Lyell Centre, Research Avenue South, Edinburgh EH14 4AP, UK

2 School of Geosciences, University of Edinburgh, The King's Buildings, James Hutton Road, Edinburgh EH9 3FE, UK

3 British Geological Survey, Nicker Hill, Keyworth, Nottingham NG12 5GG, UK 


\section{Introduction}

Probabilistic seismic hazard analysis (PSHA) is widely used to provide a quantitative description of the distribution of future ground shaking that may occur at a site. It can help to guide seismic-resistant planning and design, inform regulatory decisions and set safe industrial operating practices. The reader is referred to Reiter (1990) and McGuire (2004) for reviews. One application of PSHA is the development of a National Seismic Hazard Model (NSHM) and the accompanying national seismic hazard maps that provide seismic design guidance at a national scale (e.g. Gerstenberger et al. 2020 and references therein).

The purpose of this paper is to present the components of the 2020 NSHM for the United Kingdom (UK), together with the resulting national seismic hazard maps. Although the UK is an intraplate region with relatively low levels of seismicity, there has been a long tradition of seismic hazard analysis and development of seismic hazard maps (e.g. Lilwall 1976; Arup 1993; Musson and Winter 1996; Musson and Sargeant 2007). This was partly driven by the rapid growth of the British nuclear industry at the end of the 1970s, which prompted the need for safety cases in seismic hazard (Musson 2012a), and also by a desire to quantify the hazard from damaging earthquakes with moderate magnitudes (4-5 moment magnitude $\mathrm{M}_{\mathrm{w}}$ ), e.g. the 2007 Folkestone (4.0 $\mathrm{M}_{\mathrm{w}}$ ) earthquake (Ottemöller et al. 2009).

The most recent national seismic hazard maps for the UK were published by Musson and Sargeant (2007; hereafter referred to as MS07) and were developed in connection with the European building code Eurocode 8 (CEN 2004). The maps in MS07 show peak ground acceleration (PGA) on bedrock for the return periods of 475 and 2500 years. They indicate that the PGA hazard for 475 year return period is less than $0.02 \mathrm{~g}$ for most of the UK and Northern Ireland and slightly higher in North and South Wales (up to $0.08 \mathrm{~g}$ and $0.06 \mathrm{~g}$, respectively). For 2500 years, PGA hazard is less than $0.08 \mathrm{~g}$ across most of the country and a little higher in central Scotland (up to $0.12 \mathrm{~g}$ ), South Wales (up to $0.12 \mathrm{~g}$ ), and in North Wales (up to $0.18 \mathrm{~g}$ ).

The update of the NSHM in MS07 was prompted by two reasons. Firstly, PSHA requires updates from time to time as new data, better-constrained models and advances in the methodology become available (Frankel 1995; Grünthal et al. 2018). Since 2007, there have been significant advances particularly with respect to how ground motion and its uncertainties are modelled (see Douglas and Edwards 2016 for a review). Two types of uncertainties are recognised in PSHA: the aleatory variability that describes the inherent randomness in the seismic process; and the epistemic variability that is due to our lack of knowledge regarding the earthquake process (e.g. Atkinson et al. 2014). The aleatory variability in PSHA is incorporated by integrating over the distribution of ground-motion amplitudes about the median (e.g. Bommer and Abrahamson 2006; Atkinson et al. 2014). Epistemic uncertainties can be incorporated through the use of logic trees to capture the centre, body and range of the technically defensible interpretations of the seismic source characterisation (SSC) and ground motion characterisation (GMC) models (Budnitz et al. 1997; USNRC 2012). The variability in SSC and GMC models is fully captured by including alternative models and parameters in the logic tree where weights are assigned to each branch using expert judgement and/or data-driven approaches to reflect the relative confidence in the models and parameters (Coppersmith and Bommer 2012).

The second reason to update the NSHM is that the latest revision of Eurocode 8, which is expected to be published in 2025, requires $5 \%$ damped spectral accelerations at short period and $1.0 \mathrm{~s}$ for the revised Eurocode 8 site category A (time-averaged shear wave 
velocity for the top $30 \mathrm{~m} \mathrm{Vs} 30 \geq 800 \mathrm{~m} / \mathrm{s}$ ) as minimum hazard parameters. This is different from the current version of Eurocode 8, which anchors the seismic design spectrum to PGA for Eurocode 8 site category A (CEN 2004). Although the UK is a low seismicity region and the design seismic action is not required for standard residential and commercial buildings, design seismic action is recommended for building with high economic, social, and environmental consequences (e.g. hospitals and chemical power plants) where the exceedance of the regional hazard at a specific site is above a certain threshold (Booth et al. 2008; BS NA EN 1998-1 2008). In this context, updated national seismic hazard maps will be used to provide guidance on the application of the revision of the Eurocode 8 in the UK calibrating the design seismic requirements to the seismicity levels of the UK.

The development of the 2020 NSHM accounts for the advances that have been made in several projects to assess seismic hazard in the UK, including the 2013 European Seismic Hazard Model (ESHM13) for the SHARE (Seismic Hazard Harmonisation in Europe) project (Woessner et al. 2015), and the site-specific probabilistic seismic hazard assessments carried out for the development of new nuclear power plants (e.g. Tromans et al. 2019; Villani et al. 2020) in connection with the British Government's Nuclear Industrial Strategy (BIS 2013). Furthermore, in the last five years, many countries in Europe and worldwide have published new NSHMs, such as Switzerland (Wiemer et al. 2016), Germany (Grünthal et al. 2018), France (Drouet et al. 2020), and Australia (Allen et al. 2020). These countries also experience low levels of seismicity and share the challenge of fully capturing the epistemic uncertainties in the NSHM using sparse and limited sets of data. This challenge is a result of the short time length of earthquake observations, which span a few hundreds of years in the best case, in comparison with the seismic cycle of large earthquakes, which is of the order of thousands of years in low seismicity regions (e.g. Stein et al. 2015).

This paper gives an overview of the development of the 2020 NSHM for the UK and the resulting changes in the calculated seismic hazard with respect to previous models. The technical report by Mosca et al. (2020) provides a detailed description of the methods and results.

\section{Seismo-tectonic context}

The UK lies in the northwest part of the Eurasian plate approximately 1,500 km northeast from the Mid-Atlantic Ridge and at the northeast margin of the North Atlantic Ocean around 2,000 km south from the plate boundary between Africa and Eurasia (Fig. 1a). As a result of this geographic position, the UK is characterised by low levels of earthquake activity that is generally understood to result from the reactivation of existing faults in response to present-day forces (e.g. Musson 2012a). The nature of the crustal strain field and its relation to the observed distribution of earthquake activity in the British Isles is still not clearly understood due to the very low strain rates. Across the British Isles and the surrounding region, tectonic stresses generated at the Mid-Atlantic ridge due to forces acting perpendicular to the spreading ridge, as well as stresses resulting from the collision of Africa with Europe are expected to result in a uniform stress field with approximately northwest-southeast compression and northeast-southwest tension (e.g. Gölke and Coblentz 1996; Heidbach et al. 2016). During the Quaternary, the British Isles were affected by repeated glaciations (e.g. Lambeck 1993; Shennan et al. 2006). As a result, it has been suggested that glacio-isostatic adjustment may play 


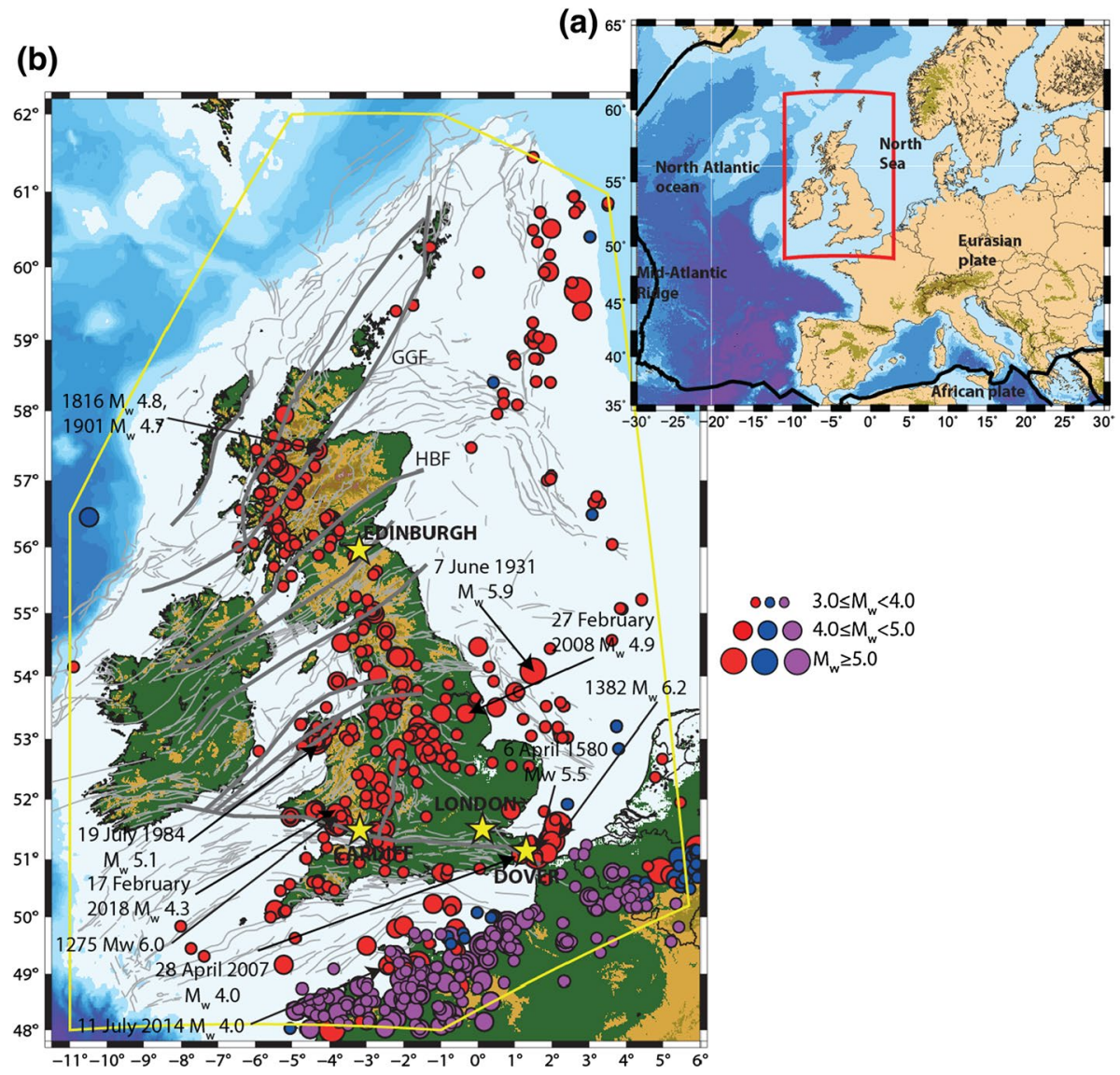

Fig. 1 a Topographic map of Europe where black lines represent the plate boundaries and the red rectangle indicates the region being considered in this study. b Seismotectonic map for the British Isles where earthquakes (mainshocks and time-dependent events) of $\mathrm{M}_{\mathrm{w}} \geq 3.0$ from the BGS catalogue, the ISC database, and the catalogue of Manchuel et al. (2018) are described by red, blue, and purple circles, respectively. The distribution of earthquakes covers the period between 842 and 2018. The yellow polygon delineates the boundaries of the study area. Faults (thin grey lines) and major tectonic structures (bold dark grey lines) are taken from Pharaoh et al. (1996), Woodcock and Strachan (2012), and Bluck et al. (1992). Yellow stars indicate sites selected for the hazard calculations in Sect. 6. GGF = Great Glen Fault; HBF $=$ Highland Boundary Fault. The topography in $\mathbf{a}$ and $\mathbf{b}$ is from the global model ETOPO1 (Amante and Eakins 2009)

a significant role in the seismicity of the region (Muir-Wood 2000; Main et al. 1999). Due to the limited amount of geodetic observations, currently, it remains unclear which is the primary factor explaining the observed nature and distribution of seismicity.

There are relatively strong variations in the spatial distribution of seismicity throughout the British Isles (Musson 2007; Baptie 2010). Earthquake activity occurs in a north-south band along the length of Britain, mainly along the western flank. This band gets wider moving south. The northeast of Britain, the northwest Atlantic margin and Ireland all show an absence of notable seismicity (Fig. 1b). The earthquake band on mainland Britain cuts across the geological terrane boundaries and activity is not confined to either particular structural blocks or boundaries between the blocks (Chadwick et al. 1996). 
The geographical distribution of instrumentally recorded earthquakes from 1970 to the present generally follows the distribution of historical seismicity over the last 300 years (Musson 2007). However, historical evidence shows that significant earthquakes have occurred in the Dover Straits, southwest Wales and around Inverness in north-east Scotland (Fig. 1b), where there has been relatively little instrumentally recorded seismicity. There is considerable evidence for damaging earthquakes in the Dover Straits over the last 1000 years, such as a $5.5 \mathrm{M}_{\mathrm{w}}$ earthquake in 1580 (GarcíaMoreno et al. 2015) and the $6.2 \mathrm{M}_{\mathrm{w}}$ earthquake in 1382 (Musson, pers. comm.). Musson (2015) also speculates that an earthquake with 6.0 Mw occurred in southwest Wales in 1275. However, there is relatively little macroseismic data for this event and both the location and magnitude are subject to large uncertainties. Earthquakes with magnitudes of 4.8 and $4.7 \mathrm{M}_{\mathrm{w}}$ occurred in Inverness in 1816 and 1901. The 1901 earthquake was felt over much of Scotland and caused substantial amounts of minor damage in Inverness, including falling chimneys and masonry. This earthquake was followed by an aftershock sequence that lasted some months (Musson 2007).

The largest instrumentally recorded earthquake in the UK catalogue occurred on 7 June $1931\left(5.9 \mathrm{M}_{\mathrm{w}}\right)$ in the Dogger Bank area of the North Sea (Neilson et al. 1984). Musson (2015) discusses the potential for larger events that may have affected the UK in historical times, including earthquakes in North Wales in 1247 and northwest Scotland in 1508, but their locations and magnitudes are highly uncertain. The largest onshore earthquake in the UK since 1970 occurred on 19 July 1984 near Yr Eifl on the Lleyn Peninsula in northwest Wales and had a magnitude of $5.1 \mathrm{M}_{\mathrm{w}}$. There have been three moderate magnitude $\left(\mathrm{M}_{\mathrm{w}} \geq 4.0\right)$ earthquakes since the end of 2007: the 4.9 $\mathrm{M}_{\mathrm{w}}$ Market Rasen earthquake on 27 February 2008; the $4.0 \mathrm{M}_{\mathrm{w}}$ Jersey earthquake on 11 July 2014; and the $4.3 \mathrm{M}_{\mathrm{w}}$ Swansea earthquake on 17 February 2018 (Fig. 1b).

The hypocentral depths of the earthquakes in the UK catalogue are distributed throughout the crust between depths of 0 and $30 \mathrm{~km}$. However, the uncertainties in the focal depths for instrumentally recorded depths can exceed $\pm 10 \mathrm{~km}$. Similarly, the catalogue does not contain uncertainties for the depths of historical earthquakes and these will likely exceed typical depth uncertainties for instrumentally recorded events. Depth estimates for historical events are based on macroseismic estimations, and while applying the same methods to modern events suggests good agreement with instrumentally determined depths, the uncertainties for events may vary widely with macroseismic data quality.

Focal mechanisms for selected earthquakes in the UK show mainly strike-slip faulting that suggests north-south to northwest-southeast compression and east-west to northeast-southwest tension (Fig. 2; Baptie 2010). These orientations appear consistent with tectonic loading from first-order plate motions that result in northwest-southeast compression and northeast-southwest tension and is supported by other stress data (e.g. Heidbach et al. 2016). For example, in Scotland, the strike of left-lateral mechanisms is similar to the orientation of tectonic features such as the northeast-southwest striking Great Glen Fault or the Highland Boundary Fault; whereas in England and Wales, focal mechanisms predominantly show either right-lateral motion on either east-west or north-south oriented fault planes.

No earthquake in the UK in the historical or instrumental record has ever produced unambiguous evidence of a surface rupture. Typical fault rupture dimensions estimated for the largest instrumentally recorded British earthquakes appear to be of the order of 1-2 km (Baptie 2010). As a result, it is difficult to accurately associate earthquakes with specific faults, particularly at depth, where the fault distributions and orientations are unclear. 
(a)

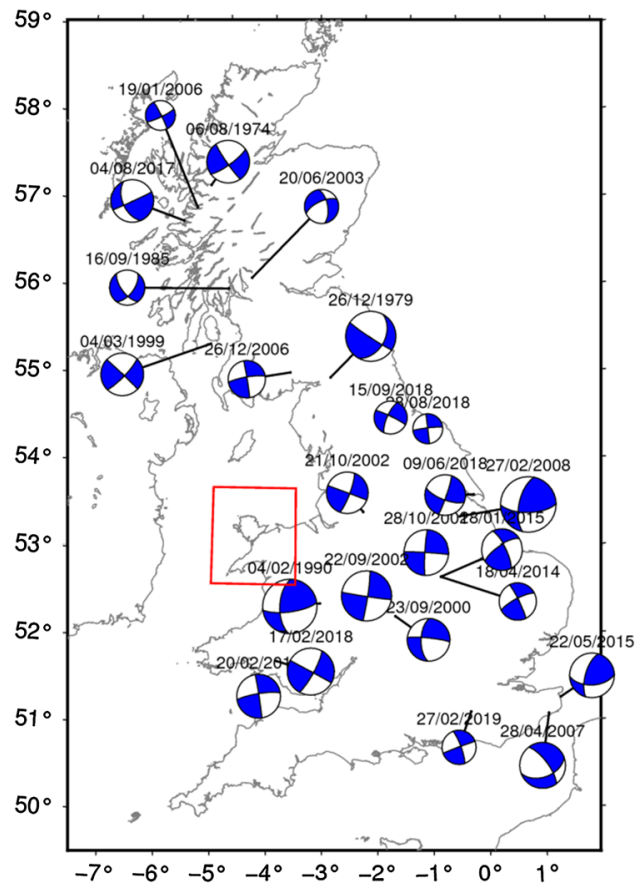

(b)

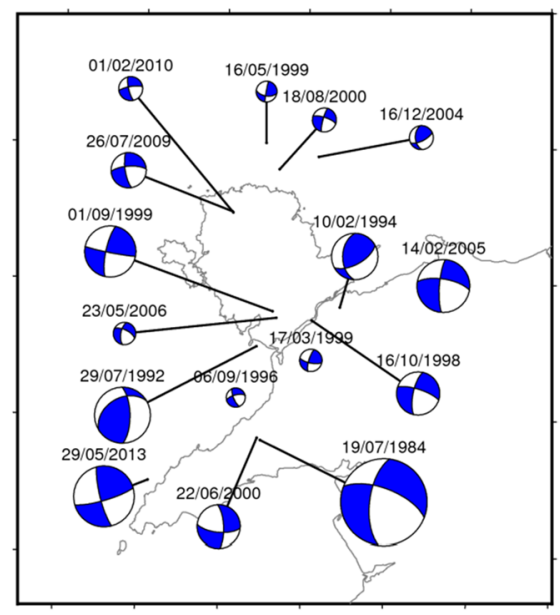

Fig. 2 a Focal mechanisms for selected earthquakes (e.g. Baptie 2010). b Focal mechanisms in North Wales shown by the red rectangle in $\mathbf{a}$. Blue and white quadrants show areas of compression and dilatation

Furthermore, seismicity may be associated with unmapped faults whose spatial extent and orientation is unknown.

\section{Earthquake catalogue}

The earthquake catalogue used in this study lies inside the polygon in Fig. 1b. It starts in $842 \mathrm{AD}$, has been extended from June 2007, as it was in MS07, to 31 August 2018, and contains 683 earthquakes (mainshocks and dependent events) of $3.0 \mathrm{M}_{\mathrm{w}}$ and above for which the origin time, location and magnitude are known. The seismic events in the catalogue come from three sources that have been merged: the British Geological Survey (BGS) catalogue, the ISC online database and the French earthquake catalogue of Manchuel et al. (2018), referred to as FCAT-17.

The BGS catalogue is the primary source for this work and includes historical and instrumental events in and around the British Isles. Earthquakes before 1970 are from Musson (1994, along with subsequent updates), which includes all events with local magnitude (ML) $\geq 4.0$ before 1969 and some onshore events of $\mathrm{ML}<4.0$. From 1970 to the present, the primary source of data is the annual bulletins of earthquake activity published by the BGS (e.g. Burton and Neilson 1980; Galloway et al. 2013). We removed the mining-induced events from the BGS catalogue by assuming that these induced earthquakes have occurred in the proximity to operating mines, have a magnitude smaller than $3.0 \mathrm{ML}$, 
and are shallow $(<5 \mathrm{~km})$ events. Events of an explosive origin due to quarrying, mining, weapon testing or disposal, naval exercises, geophysical prospecting and civil engineering have also been excluded where possible. Quarry blasts, which account for most of such events, have been removed by checking locations against known quarries and, where possible, confirming blasting times with the relevant quarry. Explosions from the detonation of ordnance or other sources mostly occur offshore and have been removed by analysing the waveform characteristics, which are different from tectonic earthquakes. For ambiguous events, information reported by relevant authorities (e.g. Coastguard), as well as other seismological agencies are also used to discriminate between natural earthquakes and explosions.

The ISC Bulletin contains global seismicity data from 1904 to the present and is based on bulletin data collected from 515 seismological agencies around the world (http://www. isc.ac.uk/). We use data from the ISC database to improve the catalogue completeness in the North Sea, the English Channel, and the border between France and Belgium. Explosions have been removed from the ISC catalogue as explained above. FCAT-17 is a parametric earthquake catalogue that merges the historical and instrumental catalogues for metropolitan France (Manchuel et al. 2018). All magnitudes are given as $\mathbf{M}_{w}$ and the catalogue is used to augment the UK data for the southernmost part of the study area. To merge the data from the three sources, we used the following hierarchy where there were duplicated events (i.e. events with similar locations and original times). The events from the BGS catalogue were given priority across the study area because these were considered to be the most well-constrained for the region, then the event from the ISC database and last the entries from FCAT-17.

It is standard practice in seismic hazard assessment to use $\mathrm{M}_{\mathrm{w}}$ (Bolt and Abrahamson 2003). To homogenise the composite earthquake catalogue in terms of $M_{w}$, we use the equations of Grünthal et al. (2009) that have been derived from earthquakes of $3.5<\mathrm{ML}<6.5$ in Central and Northern Europe. The $\mathrm{M}_{\mathrm{w}}$ values calculated using Grünthal et al. (2009) do compare relatively well with measured $\mathrm{M}_{\mathrm{w}}$ for the UK although there are very few data for earthquakes larger than 4.0 ML to extend the comparison to larger magnitudes (see Mosca et al. 2020). This magnitude relationship has also been used recently in site-specific PSHA for nuclear power plants in the UK (Tromans et al. 2019; Villani et al. 2020).

\subsection{Declustering and assessing catalogue completeness}

To decluster the earthquake catalogue and therefore to remove the time-dependent events (aftershocks and foreshocks), we use the windowing method of Burkhard and Grünthal (2009). This is based on magnitude-dependent time and space windows calibrated for the earthquake catalogue in Central Europe. Initial inspection of the results showed that in general, the time and space windows are acceptable for the UK data but in a few cases (e.g. the Torridon earthquake sequence with 2.7-3.8 $\mathrm{M}_{\mathrm{w}}$ between August 1934 and May 1936, the Kintail earthquake sequence with 2.0-4.1 $\mathrm{M}_{\mathrm{w}}$ in Western Scotland between 1974 and 1975, and the $5.1 \mathrm{M}_{\mathrm{w}}$ earthquake in the Lleyn Peninsula on 19 July 1984 with its aftershock sequence), the Burkhard and Grünthal (2009) method fails to identify aftershocks correctly. In these cases, the dependent events are removed manually. This problem may have arisen because location and magnitude uncertainties are not accounted for by the declustering process and these may be large from some historical and older instrumentally recorded earthquakes. Furthermore, the sequence of aftershocks for the 1984 Llyen event 

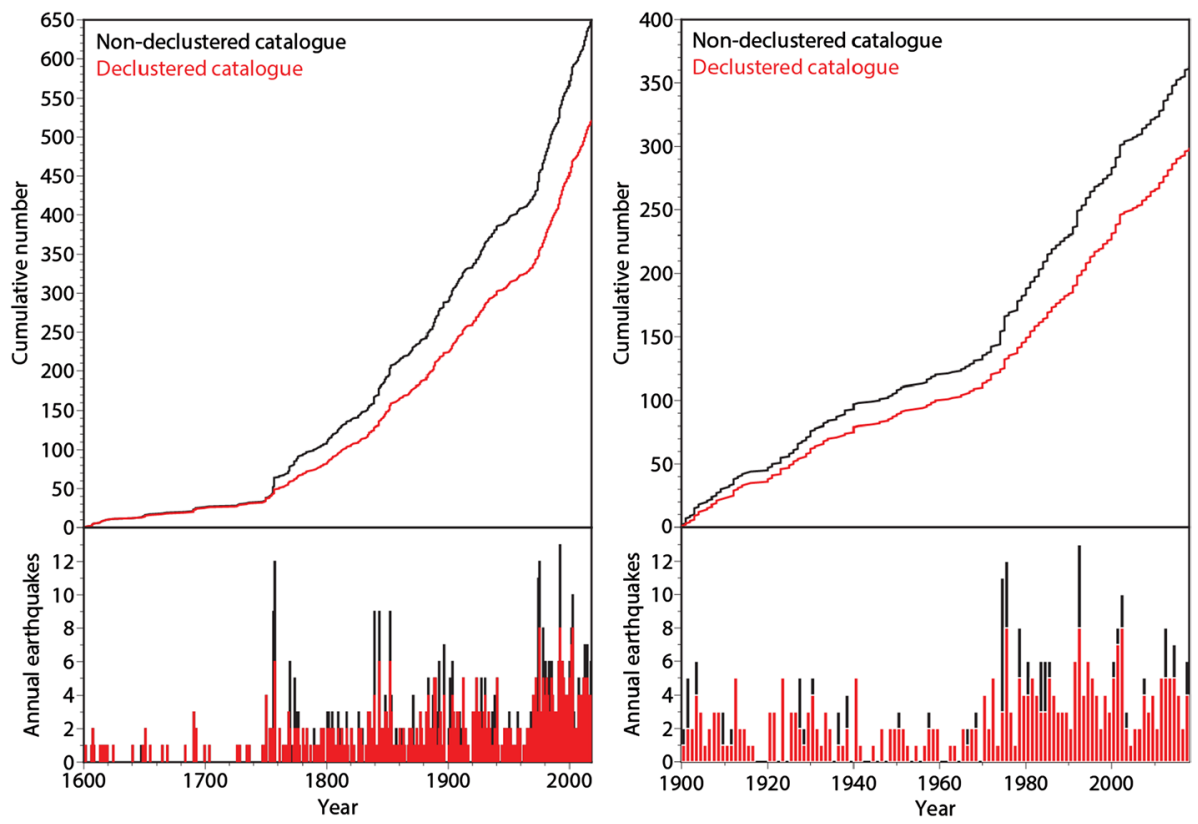

Fig. 3 Cumulative number (top panel) and annual number (bottom panel) of $\mathrm{M}_{\mathrm{w}} \geq 3.0$ earthquakes as a function of time from 1600 to 2018 on the left-hand side and from 1900 to 2018 on the right-hand side. For both, black denotes the whole catalogue and red denotes the declustered catalogue

Table 1 Completeness values for the earthquake catalogue. The completeness analysis for the North Sea is from Woessner et al. (2015)

\begin{tabular}{llll}
\hline Mc & UK & Mc & North sea \\
\hline 3.0 & 1975 & 3.7 & 1970 \\
4.0 & 1750 & 4.1 & 1890 \\
4.5 & 1700 & 4.7 & 1800 \\
5.0 & 1650 & 5.5 & 1700 \\
6.5 & 1000 & & \\
\hline
\end{tabular}

is relatively long for an earthquake of that size. Stein et al. (2015) suggest that the duration of aftershock sequences in intraplate regions may be longer than in interplate regions and this may also contribute to the failure of the declustering process in this case. Figure 3 shows the cumulative and annual number of earthquakes of $3.0 \mathrm{M}_{\mathrm{w}}$ and above in the catalogue before and after declustering. After declustering, the total number of mainshocks of $M_{w} \geq 3$ is 547 (out of 683 events of $3 M_{w}$ and above). We also test the temporal Poisson behaviour of the declustered catalogue with $\mathrm{M}_{\mathrm{w}} \geq 4.0$ from 1750 to the present as discussed below. This is the period for which the catalogue is assumed to be complete for $M_{w} \geq 4.0$ (Table 1). Using a chi-square test (e.g. Luen and Stark 2012), we find that the null hypothesis that the earthquake distribution is Poissonian cannot be rejected with a $95 \%$ confidence level.

There are several methods available to assess the completeness of earthquake catalogues including Wiemer and Wyss (2000), Cao and Gao (2002) and Woessner and Wiemer (2005). However, Roberts et al. (2015) suggest that catalogues should contain a minimum of 200 events above the completeness magnitude to apply these methods and produce 
statistically meaningful results. Since our catalogue contains a relatively small number of events we have to adopt a pragmatic approach to this problem. The historical catalogue for the UK has changed little in recent years, so for the period before 1970, we adopt the same completeness values as MS07 (Table 1). For more recent earthquakes, the level of completeness for the UK is largely determined by the level of instrumental monitoring in the region. The development of the instrumental seismic monitoring network in the UK started in 1969 when a local seismic network consisting of seven stations (LOWNET) was deployed in Central Scotland (Crampin et al. 1970), and continued to expand through the 1980s and 1990s. The modelled detection capability of the instrumental network suggests in the 1970s there were parts of mainland Britain where the detection threshold exceeded $3.3 \mathrm{M}_{\mathrm{w}}$. In the Eighties, the network was capable of detecting events with a magnitude of $2.0 \mathrm{M}_{\mathrm{w}}$ or above across nearly all of mainland Britain (see Fig. 4 in Mosca et al. 2020). Note that this modelling does not take into account the possible failure of individual monitoring stations and the resulting impact on detection capability. With this in mind, we assume that the instrumental catalogue for the UK and the English Channel is complete for magnitudes of $3.0 \mathrm{M}_{\mathrm{w}}$ and above from 1975 to the present (Table 1).

To test the validity of the completeness thresholds in Table 1, we compare the observed frequency-magnitude distribution (FMD) and the Gutenberg-Richter frequency-magnitude law (Gutenberg and Richter 1954) for the entire catalogue, the pre-1975 portion (i.e. dominated by pre-instrumental data) and the post-1975 catalogue portion (instrumental data only) for the UK region, excluding the North Sea. Our hypothesis is that if the assessment of completeness is appropriate then the $b$-value for the entire catalogue and the two 'sub-catalogues' will be roughly the same. To determine the activity rate and $b$-value in the FMDs, we use a penalised maximum likelihood procedure (Johnston et al. 1994; see Sect. 4.2). Figure 4 shows that the $b$-values of the three catalogue variants are very similar suggesting that the proposed completeness thresholds in Table 1 are suitable and that each sampled period contains roughly the same proportion of larger and smaller events.

In the North Sea region, there is a severe lack of data before the 1970s because only a few seismometers were operating in the northern UK and Norway. For this region, we use the results of the completeness analysis for Northern Europe undertaken by Woessner et al. (2015). According to this, our catalogue for the North Sea region can be considered to be complete for $3.7 \mathrm{M}_{\mathrm{w}}$ and above since 1970 (Table 1).

\section{Seismic source characterisation model}

The SSC model aims to describe the location, size, and frequency of future earthquakes through a set of parameters such as the geometry of the seismic sources, maximum earthquake magnitude, and recurrence parameters drawn from the FMD of the seismicity in each source (e.g. Budnitz et al. 1997). The study area is divided into a series of seismic sources. In each source, the seismic activity is considered to be spatially uniform and earthquakes have an equal chance of occurring at any point (e.g. Reiter 1990). We use a single-source model that is based on the current understanding of crustal geology, tectonic processes and historical seismicity constrained by geological mapping, regional stress measurements and models, geophysical surveys, macroseismic data and instrumental recordings of seismicity. There is insufficient information to define individual fault sources so our SSC model consists of zones only. The zonal approach also allows potentially buried, and therefore unknown, fault structures to be accounted for. 

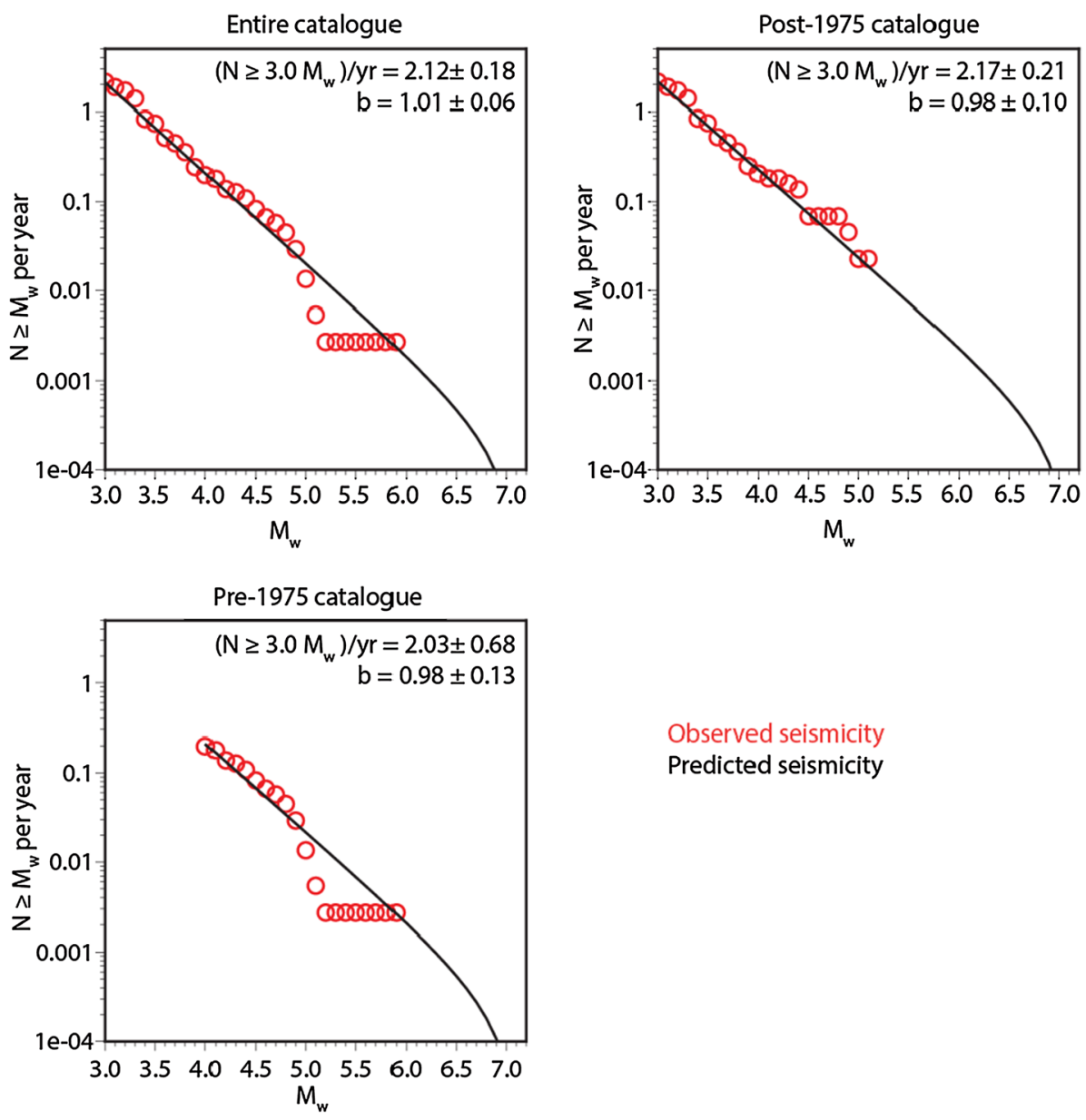

Observed seismicity

Predicted seismicity

Fig. 4 FMD calculated for the UK region using the completeness values in Table 1. The red circles are based on the observed FMD and the black line shows the predicted FMD using the Gutenberg-Richter law for the recurrence parameters, together with their standard deviation, given on the graph

The model consists of 22 source zones and draws heavily on previous regional source models, including MS07 and the ESHM13 (Woessner et al. 2015; see Fig. 5). Both MS07 and ESHM2013 were influenced by a study of the seismo-tectonics of the UK by Chadwick et al. (1996). The zonation for the present study takes the ESHM13 zone boundaries as its starting point but we have made some modifications in light of recent developments in the understanding of tectonics in the UK. For example, the latest geophysical and geological data and models resolve the Malvern Lineament well (e.g. Pharaoh 2018) and so the boundaries between MMCW, MMCE and PENN have been adjusted to reflect this (see Fig. 5a). Also, since the Sangatte Fault, which runs through the Dover Straits from Sangatte (northeast France) to south-east England is the probable source of the 1580 earthquake (5.5 $\mathrm{M}_{\mathrm{w}}$; Camelbeeck et al. 2007) and the 2007 Folkestone earthquake (Ottemöller et al. 2009), the zone covering the Dover Straits (DOVE) has been extended slightly to 


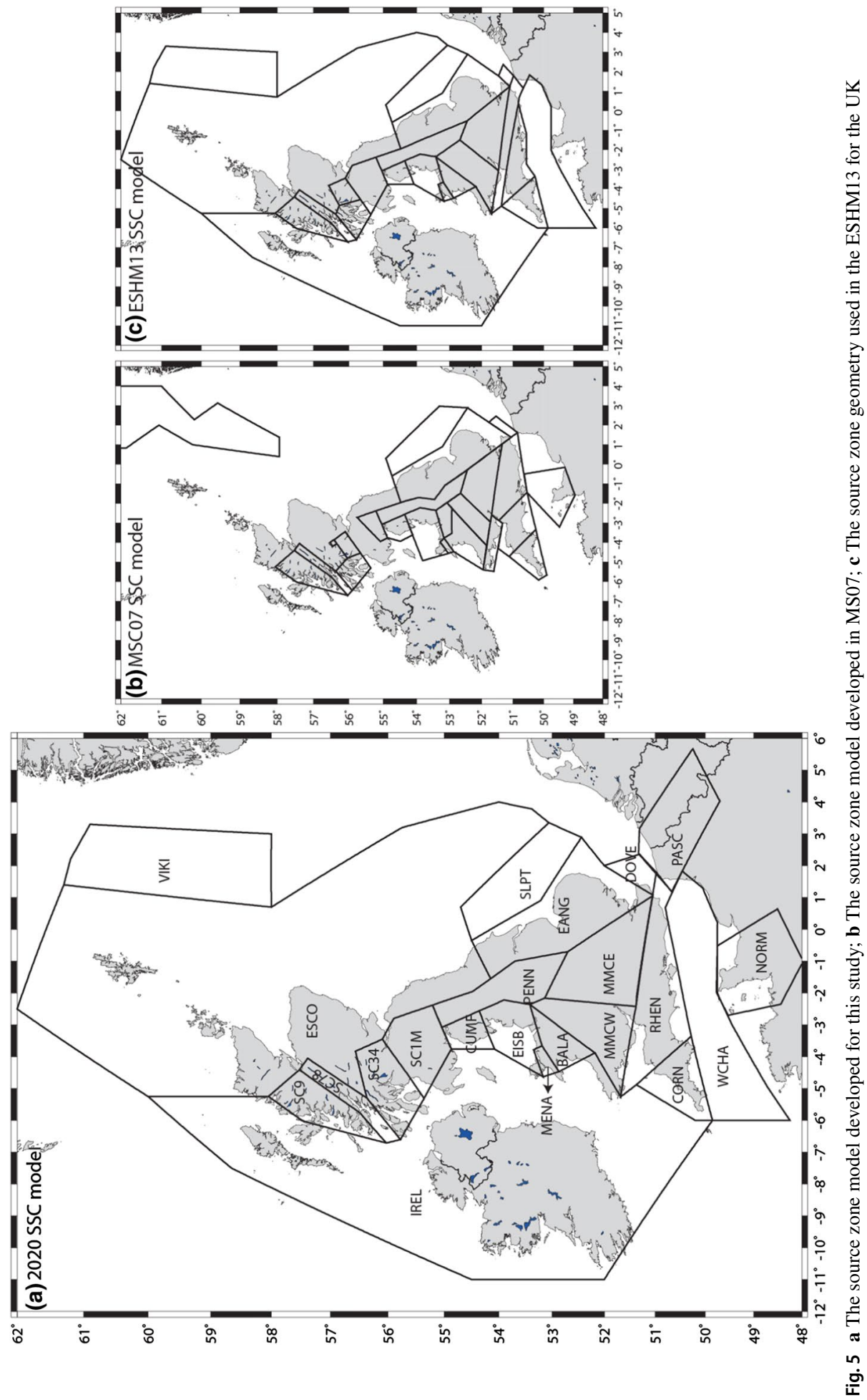


the west to include the 2007 event and north to include another large $\left(\sim 6.0 \mathrm{M}_{\mathrm{w}}\right)$ historical (1382) event in the Dover Strait, compared with the same zone in ESHM13.

We use the depth distribution determined by MS07 because the general understanding of the distribution of the hypocentral depths of British earthquakes has not changed since that report was published. In MS07, the earthquakes are assumed to have hypocentral depths between 5 and $20 \mathrm{~km}$, with a modal depth of $15 \mathrm{~km}$ (see Table 2).

The faulting in each zone has a weighted distribution of possible styles and orientations. Given the stress conditions in the UK, it is assumed here that future significant earthquakes are most likely to be strike-slip events with either north-south or east-west focal mechanisms and these orientations are equally weighted in the model. This is consistent with what has been observed predominantly for larger events in the last 30 years of UK seismicity (Baptie 2010).

\subsection{Maximum magnitude}

Maximum magnitude (Mmax) defines the size of the largest possible earthquake in the region under investigation. This is often highly uncertain, although, in a broad sense the maximum magnitude is theoretically limited by fault length because any large earthquake requires a sufficiently large structure or system of interacting structures to host it. Defining Mmax in intraplate regions is particularly challenging (Holschneider et al. 2011, 2014) since the recurrence interval of large earthquakes is of the order of several hundreds to thousands of years due to the low rate of deformation and greatly exceeds the relatively short duration of any earthquake catalogue based on historical data. As a result, it is quite likely that the largest possible earthquake may not be included in the records.

The UK historical earthquake catalogue includes two earthquakes with magnitudes greater than or equal to $6.0 \mathrm{M}_{\mathrm{w}}$ : a magnitude $6.2 \mathrm{M}_{\mathrm{w}}$ event in the Dover Straits in 1382 and a magnitude $6.0 \mathrm{M}_{\mathrm{w}}$ event in South Wales in 1275. Significant uncertainties are associated with both the locations and the magnitudes of these events. The largest earthquake for which a magnitude can be estimated reliably is the Dogger Bank event that occurred on 7 June $1931\left(5.9 \mathrm{M}_{\mathrm{w}}\right)$. Earthquakes of $\mathrm{M}_{\mathrm{w}} \geq 6.0$ have occurred in analogous tectonic regions. The largest earthquake, which is known to be observed in north-west Europe, is the 1356 Basel earthquake in Switzerland $\left(6.6 \pm 0.5 \mathrm{M}_{\mathrm{w}}\right.$; Fäh et al. 2011). Other examples of large earthquakes in low seismicity regions are the three principal earthquakes in the 1811-1812 New Madrid sequence (6.7 $\mathrm{M}_{\mathrm{w}}, 6.5 \mathrm{M}_{\mathrm{w}}$ and $6.8 \mathrm{M}_{\mathrm{w}}$ for the 16 December 1811, 23 January 1812 and 7 February 1812 earthquakes, respectively; Hough and Page 2011) and the 1886 Charleston earthquake in South Carolina (7.3 $\pm 0.3 \mathrm{M}_{\mathrm{w}}$; Johnston 1996).

There is no standard procedure for determining Mmax for PSHA (for a review, see Wheeler 2009 and Meletti et al. 2009). MS07 used a weighted maximum magnitude distribution for onshore areas (between 5.5 and $6.5 \mathrm{M}_{\mathrm{w}}$, with the highest weighting for $6.0 \mathrm{M}_{\mathrm{w}}$ )

Table 2 Depth distribution used in the NSHM for the UK

\begin{tabular}{ll}
\hline Depth $[\mathrm{km}]$ & Weight \\
\hline 5 & 0.1 \\
10 & 0.25 \\
15 & 0.4 \\
20 & 0.25 \\
\hline
\end{tabular}


and offshore areas (6.0-6.5 $\mathrm{M}_{\mathrm{w}}$ with the highest weighting again on $6.0 \mathrm{M}_{\mathrm{w}}$ ) based on the expert judgement from analogous regions. Here we use the Mmax distribution proposed for the British Isles by Meletti et al. (2009) for the ESHM13 model (Table 3). This was determined using the statistical approach of Johnston et al. (1994 and updated in EPRI 2012) to determine the Mmax distribution in areas of low seismicity. We use the Mmax distribution shown in Table 3 for all zones. The magnitudes in the distribution are higher than those used by MS07 to account for new information on the occurrence of earthquakes with magnitudes of $6.0 \mathrm{M}_{\mathrm{w}}$ or greater (see Musson 2015) becoming available since 2007 and the examples of the occurrence of large earthquakes in analogous regions. This indicates that we cannot rule out future earthquakes of magnitude larger than $6 \mathrm{Mw}$.

\subsection{Recurrence statistics}

The relationship between the magnitude and number of earthquakes in a given region and time period generally can be expressed by the Gutenberg-Richter frequency-magnitude law (Gutenberg and Richter 1954):

$$
\log _{10} N=a-b M
$$

where $N$ is the number of earthquakes above a given magnitude $\mathrm{M}$. The constant $a$, is a function of the total number of earthquakes in the sample and is commonly normalised over a period of time, such as a year. The constant $b$ gives the relative number of events of different magnitudes and is commonly referred to as the $b$-value. In general, $b$-values are close to unity meaning that for each unit increase in magnitude, the number of earthquakes reduces tenfold. Cornell and Vanmarcke (1969) define a truncated version of the Gutenberg-Richter law where the range of earthquake magnitudes is limited by a lower and upper bound:

$$
N \geq M=10^{a\left(M_{0}\right)} \frac{e^{-\beta\left(M-M_{0}\right)}-e^{-\beta\left(\text { Mmax }-M_{0}\right)}}{1-e^{-\beta\left(\text { Max }-M_{0}\right)}}
$$

where $\beta=b^{*} \ln (10), \mathbf{M}_{0}$ is the minimum magnitude for the recurrence statistics, Mmax is the maximum magnitude, $a\left(M_{0}\right)$ is the log of the number of earthquakes of magnitude $\mathrm{M}_{0}$ and above.

We use the penalised maximum likelihood procedure (PMLP) described in Johnston et al. (1994) to estimate the FMD for the seismic source model. This accounts for different time windows of the catalogue completeness, the uncertainty in $a$ and $b$ and the correlation between them, and a weighted prior constraining the $b$-value when there are too few earthquakes in the source zone for a reliable estimate to be made. The $b$-value is introduced as a penalty function for which the weight can be specified. Using Eq. (2), the results from the PMLP are expressed by a $5 \times 5$ matrix of possible values for $a$ and $b$, determining 25

Table 3 Distribution of the maximum magnitude (Mmax) used in the NSHM for the UK

\begin{tabular}{ll}
\hline Mmax & Weight \\
\hline 6.5 & 0.5 \\
6.7 & 0.2 \\
6.9 & 0.2 \\
7.1 & 0.1 \\
\hline
\end{tabular}


triplets of activity rate, $b$-value and their weight. We did not apply the standard error for individual magnitude estimates because the magnitude uncertainty of the earthquakes is not assessed uniformly in the three sources used to construct the catalogue for this work. EPRI (2012) and Musson (2012b) recognise that care should be taken when magnitude uncertainties are accounted for in the recurrence statistics, especially when an earthquake catalogue merges many sources and contains more than one original magnitude scale. This is to avoid over- or under-estimating the activity rate and the $b$-value in the area under consideration.

We apply the PMLP to each zone in the source model using the completeness thresholds in Table 1. The minimum magnitude $\left(\mathrm{M}_{0}\right.$ in Eq. 2$)$ for the recurrence calculations is 3.0 $\mathrm{M}_{\mathrm{w}}$. For the maximum magnitude (Mmax in Eq. 2) we use a value of 7.1. This is the largest value in the Mmax distribution used for the hazard calculations (see Table 3). However, the choice for Mmax is not critical for the results because it has little influence on the estimation of the activity rates and $b$-values of the source model (Musson 2012b). We use the $b$-value determined in Sect. 3.1 (1.0) as the prior for this analysis.

The recurrence statistics determined for each of the zones in the source model are shown in Fig. 6 where the length of the error bars is inversely proportional to the number of observations above a certain magnitude in the catalogue for that zone. This gives a general indication of the uncertainties in the long-term recurrence rate for that magnitude. The 25 recurrence parameters in the probability distribution of the FMD are described by the grey lines in Fig. 6, whereas the black lines are the FMD from the weighted mean of the 25 recurrence parameters. The sum of the weighted mean of $\left(\mathrm{N} \geq 3.0 \mathrm{M}_{\mathrm{w}}\right) / \mathrm{yr}$ estimates for the individual zones in the UK region (excluding VIKI and NORM) is $(\mathrm{N} \geq 3.0$ $\left.\mathrm{M}_{\mathrm{w}}\right) / \mathrm{yr}=2.07$ and therefore approximately equal to the regional estimate of $\left(\mathrm{N} \geq 3.0 \mathrm{M}_{\mathrm{w}}\right) /$ $\mathrm{yr}=2.12 \pm 0.18$ in Fig. 4. This consistency gives some confidence in the $\left(\mathrm{N} \geq 3.0 \mathrm{M}_{\mathrm{w}}\right) / \mathrm{yr}$ estimates for individual zones. For zones SLPT, ESCO and VIKI we use the results of the completeness analysis for the North Sea. Although ESCO also includes eastern Scotland, all the earthquakes recorded in this zone have occurred offshore. For this reason, we adopt the completeness estimates for the North Sea for this zone. For zones BALA and ESCO, which contain no earthquakes within the completeness thresholds, the $b$-value is fixed to be the chosen prior of 1.0 and $\left(\mathrm{N} \geq 3.0 \mathrm{M}_{\mathrm{w}}\right) / \mathrm{yr}$ depends on the area of the zone and the average rate for the low seismicity regions of Central and Northern Europe (Musson 2011). The seismicity in zones MMCW in Mid and South Wales and MENA in North Wales shows a "hump", or departure from a straight line, around $4.5 \mathrm{M}_{\mathrm{w}}$ with more earthquakes of $\mathrm{M}_{\mathrm{w}} \geq 4.5$ than are predicted by the Gutenberg-Richter FMD between 3.0 and $5.0 \mathrm{M}_{\mathrm{w}}$ (see Figs. 6 and 7). This "semi-characteristic" behaviour of the seismicity in these regions was first observed by MS07, and later by Tromans et al. (2019) and Villani et al. (2020) and can be explained by a 'bipartite FMD' (see Musson 2015; Mosca et al. 2019) as shown in Fig. 7. This means that the seismicity of MMCW and MENA can be modelled as two populations of earthquakes with distinct FMDs. The first is a population of "normal" earthquakes represented by the levels of seismicity in the magnitude range between 3.0 and 4.5 $\mathrm{M}_{\mathrm{w}}$. The second population consists of earthquakes in the magnitude range of 4.5-7.1 $\mathrm{M}_{\mathrm{w}}$. The $b$-value is very similar for the two populations of earthquakes identified in MMCW and MENA. Any attempt to model the seismicity by a single FMD was found inevitably to underestimate the number of earthquakes around 4.5-5.0 $\mathrm{M}_{\mathrm{w}}$, a hazard-critical range for the UK (Fig. 7). Although this behaviour may be because the earthquake catalogue is not long enough to adequately reflect the long-term hazard in the region, we take a pragmatic decision to use the bipartite FMD as it fits the data in these two zones and reduces the 

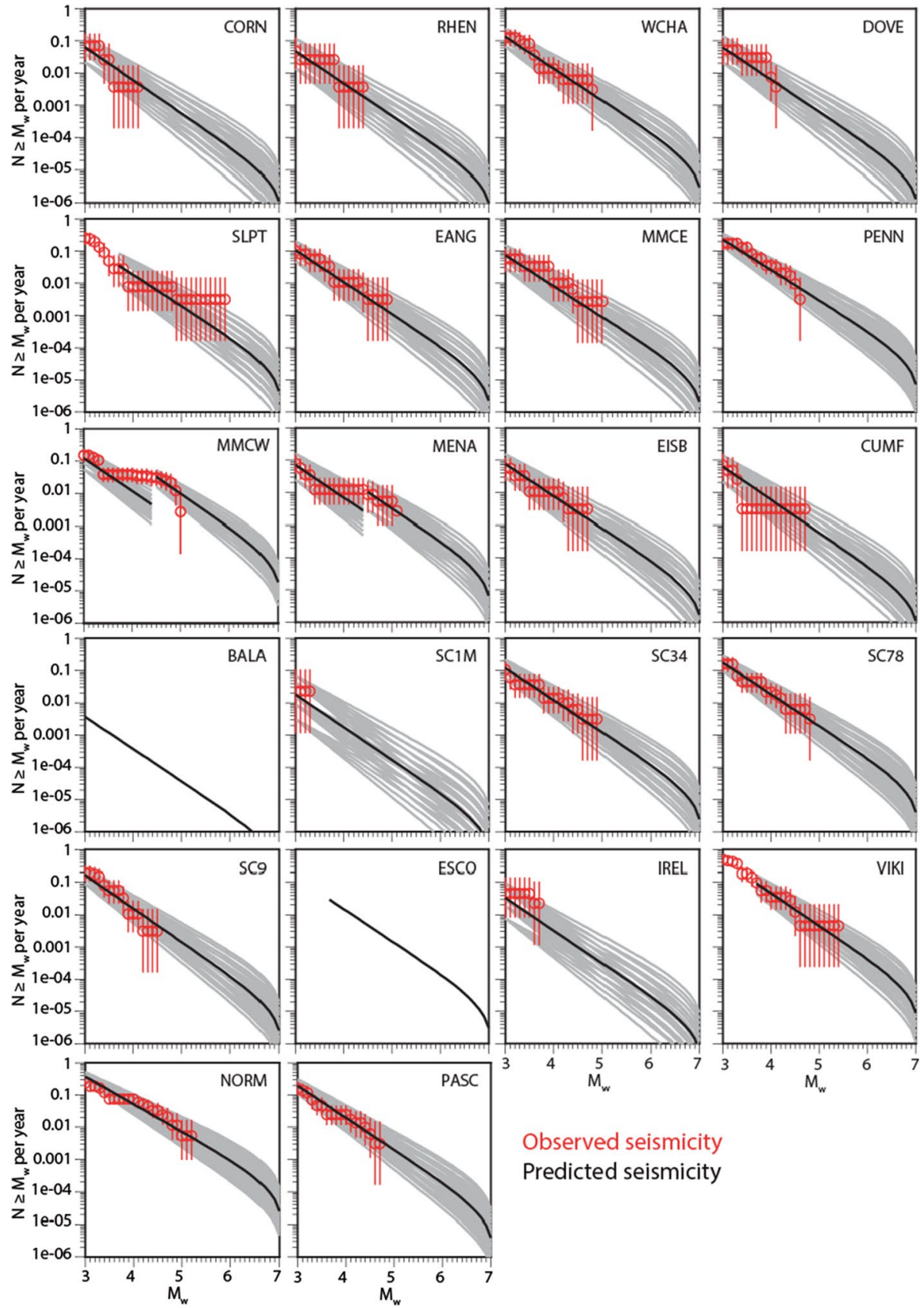

Observed seismicity

Predicted seismicity

Fig. 6 FMD for each of the zones in the source model. The grey lines describe the 25 recurrence parameters in the probability distribution of the FMD computed using the PMLP 

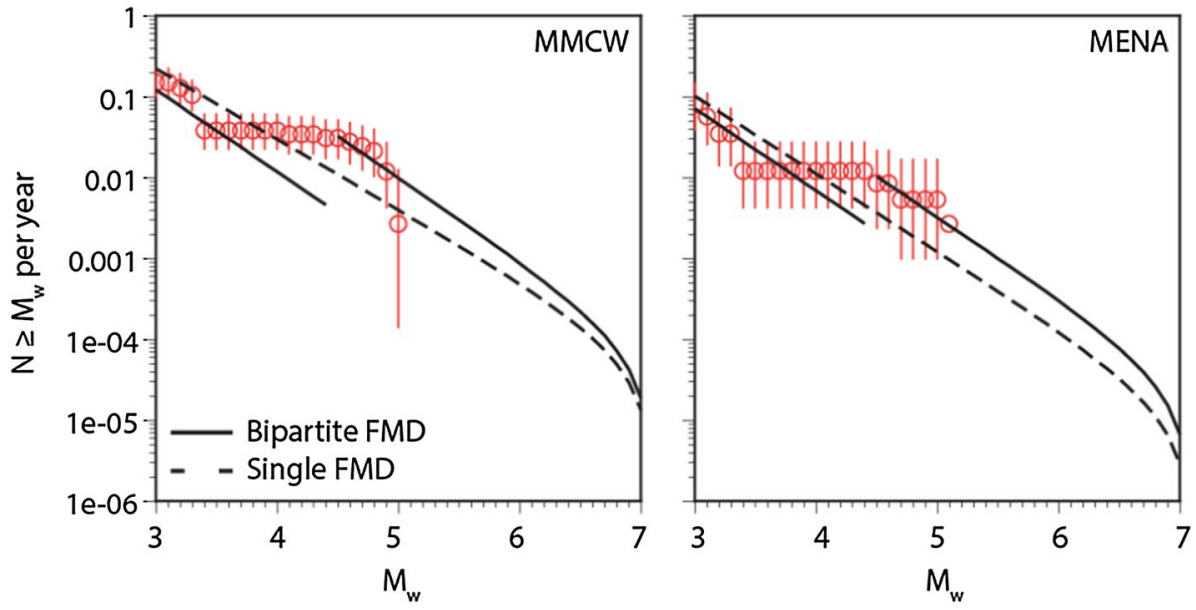

Fig. 7 Magnitude-frequency recurrence for the source zones MMCW and MENA using the bipartite FMD (solid lines) and the single FMD (dashed lines)

possibility of underestimating the number of earthquakes of $\mathrm{M}_{\mathrm{w}} \geq 4.5$ in North and South Wales.

\section{Ground motion characterisation model}

The GMC model describes the value(s) of the ground motion parameter of interest at a site resulting from all possible earthquake scenarios. Constructing the GMC model is one of the most challenging aspects of seismic hazard assessment because it significantly influences the hazard estimates. Moreover, capturing the associated aleatory and epistemic uncertainties in the GMC model adequately is very difficult with limited data. The most common way to capture the epistemic uncertainties in a GMC model is to use multiple GMPEs (ground motion prediction equations) in a logic tree that captures the centre, body, and range of technically defensible interpretations (Budnitz et al. 1997; Atkinson et al. 2014). Each GMPE is assigned a weight defined by data-driven approaches and/or expert judgements (e.g. Delavaud et al. 2012). Care is required in the design of the logic tree, especially with regard to which and how many branches to include in order to fully characterise the epistemic uncertainty. Bommer and Scherbaum (2008) argue that because the alternative GMPEs selected to populate the ground motion logic tree are often derived from the same dataset, multi-GMPE logic tree does not fully capture the epistemic uncertainty in the median prediction of the GMC model. In the last few years, the backbone approach has emerged as a way to achieve this. It is based on the selection of one or more GMPEs, which is referred to as the 'backbone model'. The median predictions of the backbone model are then scaled up and down to capture the epistemic uncertainties in the median ground motion (e.g. Atkinson et al. 2014; Goulet et al., 2017; Douglas 2018). This approach requires sufficient data to calibrate the backbone model to the region of interest.

The development of the GMC model is the result of a workshop between specialists on ground motion modelling and the members of the project team in September 2018 and informal advice from these experts throughout the project. Although the backbone approach 
Table 4 Logic tree for the median prediction of the GMC model developed for the sitespecific PSHA for the Hinkley Point C (Tromans et al. 2019) and also used in this study

\begin{tabular}{ll}
\hline GMPE & Weight \\
\hline Atkinson and Boore (2006) & 0.1 \\
Rietbrock et al. (2013) & 0.1 \\
Bindi et al. (2014) & 0.3 \\
Boore et al. (2014) & 0.3 \\
Cauzzi et al. (2015) & 0.2 \\
\hline
\end{tabular}

was explored to characterise the GMC model for this work, the multi-GMPE logic tree approach implemented in Tromans et al. (2019) was preferred for use in the UK NSHM. The GMC model of Tromans et al. (2019), was developed for the new nuclear site at Hinkley Point C (HPC) in Somerset (see Table 4). This consists of five GMPEs: the stochastic model of Atkinson and Boore (2006), which is modified in Atkinson and Boore (2011) to account for more data from moderate earthquakes and is valid for stable continental regions; the GMPEs of Boore et al. (2014), Bindi et al. (2014), and Cauzzi et al. (2015) that are valid for active shallow crustal regions; and the stochastic model of Rietbrock et al. (2013), which was developed specifically for the UK. The weights given to each GMPE by Tromans et al. (2019) were based on expert judgement because a comparison of the predictions made using the GMPEs with the available ground motion data for the UK could not determine which best predicted the observations. Tromans et al. (2019) assign a low weight (0.1) to the stochastic GMPEs of Atkinson and Boore (2006) and Rietbrock et al. (2013) because these models are poorly constrained at short distances. The GMPEs of Boore et al. (2014) and Bindi et al. (2014) are given the highest weight (0.3) because of their good performance in statistical tests in a shortlist of 12 GMPEs considered to be possible candidates for use in the HPC PSHA. The GMPE of Cauzzi et al. (2015) is given a weight of 0.2 because it performs less well than Boore et al. (2014) and Bindi et al. (2014) (for further information, see Tromans et al. 2019).

\subsection{Vs-K $K_{0}$ adjustment}

GMPEs used for estimating earthquake ground motions are usually based on empirical data from regions where there are large numbers of recordings. As a result, these GMPEs represent the site conditions of the specific region(s) for which they were derived. Ideally, when applying a GMPE from a given host region to a specific target site or region, the GMPE should be adjusted to account for differences between the host and the target (Douglas and Edwards 2016). This process is often referred to as Vs- $\kappa_{0}$ (or host-to-target) adjustment since it needs to account for both the effects of elastic amplification due to shear wave velocity structure and near-surface attenuation at a site. The near-surface site-specific attenuation is described by the parameter $\kappa_{0}$ that represents the attenuation of shear waves at a given site as a result of the physical properties of the near-surface rocks and soils.

In this work, we follow the approach of Al Atik et al. (2014) that uses the inverse random vibration theory (IRVT) to transform the response spectrum calculated using a given GMPE for a specific earthquake scenario into a compatible Fourier amplitude spectrum (FAS). This methodology allows us to compute the $\kappa_{0}$ values for the host region. Then, the host-to-target adjustments are applied to the FAS before recalculating the response spectra 
using random vibration theory (RVT). It requires no assumptions about the background seismological model (e.g. stress drop and attenuation model) for the host and target sites.

For this study, the target Vs30 is $800 \mathrm{~m} / \mathrm{s}$ across the whole of the UK. This value marks the transition from soil class A (Vs30 $>800 \mathrm{~m} / \mathrm{s})$ to class B $(350 \mathrm{~m} / \mathrm{s}<\mathrm{Vs} 30<800 \mathrm{~m} / \mathrm{s}$ ) in Eurocode 8 (CEN 2004) and is required in the forthcoming revision. The input parameters required for the Vs- $\kappa_{0}$ adjustments are the Vs profile and the $\kappa_{0}$ parameter for the target site and the host region for the GMPEs. We consider the generic Vs profile given for the target value of Vs30=800 m/s using the equations of Cotton et al. (2006). This provides a smooth velocity profile where the velocities at specific depths are interpolated from the generic models of Boore and Joyner (1997). Between these depths, the velocities are represented by a power-law model. The target $\kappa_{0}$ value is computed for the target $\mathrm{Vs} 30=800 \mathrm{~m} / \mathrm{s}$ using the empirical relationship between Vs30 and $\kappa_{0}$ of Van Houtte et al. (2011), which was derived from a large number of measurements worldwide. For our chosen Vs30, we estimate a value for $\kappa_{0}$ of $0.027 \mathrm{~s}$. We use the standard deviation of 0.55 in $\ln \left(\kappa_{0}\right)$ (Van Houtte et al. 2011) to estimate the lower and upper bounds for $\kappa_{0}$, i.e. 0.016 and $0.047 \mathrm{~s}$, respectively. This allows us to account for epistemic uncertainty in $\kappa_{0}$, though we do not include any uncertainty in the target Vs30. The three values of $\kappa_{0}(0.027,0.016$, and $0.047 \mathrm{~s}$ ) are assigned weights of $0.6,0.2$, and 0.2 following a three-point approximation to a normal distribution (Miller and Rice 1983). The best estimate of $\kappa_{0}=0.027 \mathrm{~s}$ agrees with $\kappa_{0}=0.030 \mathrm{~s}$ for $760 \leq \mathrm{Vs} 30 \leq 1100 \mathrm{~m} / \mathrm{s}$ estimated by Villani et al. (2019) using the recordings of ground motions from sites across the UK.

We use a host Vs30 of $800 \mathrm{~m} / \mathrm{s}$ for the empirical GMPEs (i.e. Boore et al. 2014; Bindi et al. 2014; and Cauzzi et al. 2015). This eliminates any amplification differences due to the shear wave velocity by using the same Vs profile for both host and target. The Vs profile for the GMPE of Rietbrock et al. (2013) is the generic Vs profile for the UK given by Booth et al. (2001). We then apply the Quarter Wavelength method (Boore 2003) to estimate frequency-dependent site amplification factors for the target velocity profile and the Booth et al. (2001) model. Amplification factors for Atkinson and Boore (2006) are given in Table 4 of their publication.

Response spectra are calculated using each GMPE for different earthquake scenarios with different magnitude and distance combinations. These scenarios were selected by doing a preliminary disaggregation of the hazard at four selected sites that are located in regions with different levels of hazard in the UK (see Sect. 6). Since the Vs- $\kappa_{0}$ adjustment factors are more important at short distances and high frequencies (Al Atik et al. 2014), we select nine earthquake scenarios based on the disaggregation analysis in the high-frequency range: $M_{w}=4.0,5.0$, and 6.0, and Joyner-Boore distances Rjb=5, 15, and $25 \mathrm{~km}$. The final Vs $-\kappa_{0}$ adjustments for the GMPE is the average from all nine scenarios.

The average $\kappa_{0 \text {,host }}$ values calculated using IRVT for the five selected GMPEs are shown in Table 5. For the three empirical GMPEs (Bindi et al. 2014; Boore et al. 2014; and Cauzzi

Table 5 Average $\kappa_{0 \text {,host }}$ values for the five GMPEs in the ground motion model

\begin{tabular}{ll}
\hline GMPE & $\kappa_{0, \text { host }}[\mathrm{s}]$ \\
\hline Atkinson and Boore (2006) & $0.0164 \pm 0.0027$ \\
Rietbrock et al. (2013) & $0.0102 \pm 0.0027$ \\
Bindi et al. (2014) & $0.0375 \pm 0.0057$ \\
Boore et al. (2014) & $0.0374 \pm 0.0048$ \\
Cauzzi et al. (2015) & $0.0347 \pm 0.0035$ \\
\hline
\end{tabular}


Fig. $8 \mathrm{Vs}-\kappa_{0}$ adjustment factors for the GMPEs in the ground motion model. The solid lines show adjustments for the median target $\kappa_{0}$ value, while the dotted and dashed lines show the calculated adjustments for the lower and upper limits of our target $\kappa_{0}$. GMPEs are abbreviated as follows: $\mathrm{AB} 06=$ Atkinson and Boore (2006); RSE13 = Rietbrock et al. (2013); BSSA14= Boore et al. (2014); BIN14 = Bindi et al. (2014); CAU15= Cauzzi et al. (2015)

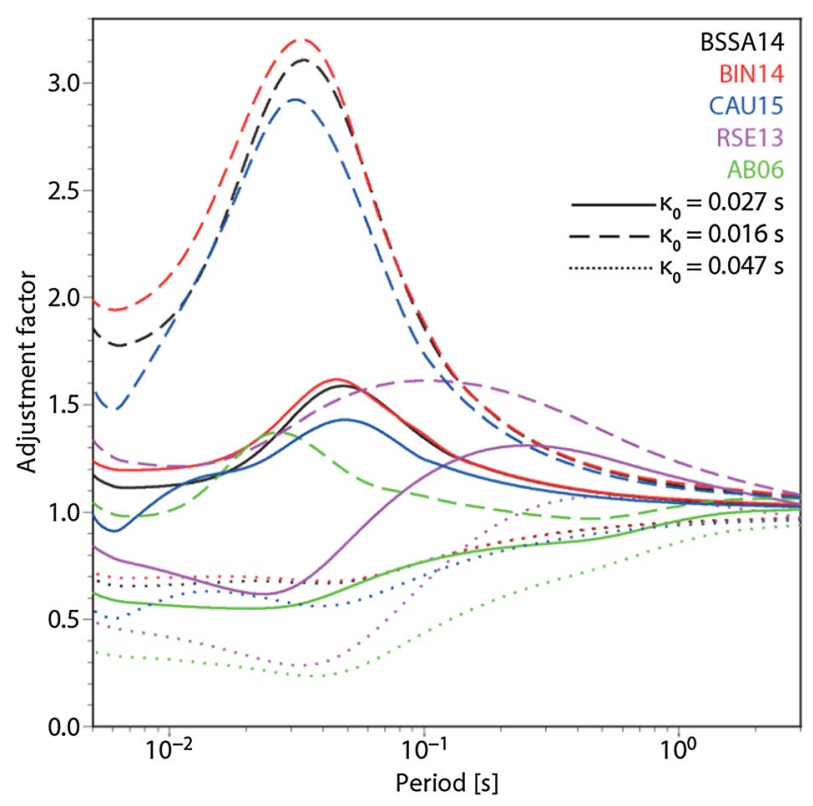

et al. 2015), the average $\kappa_{0 \text {,host }}$ values are all similar $(\sim 0.350-0.375 \mathrm{~s})$, slightly greater than our target $\kappa_{0}$ value of $0.027 \mathrm{~s}$. The average $\kappa_{0 \text {,host }}$ values for the two stochastic GMPE's (Atkinson and Boore 2006; Rietbrock et al. 2013) are both smaller than the target $\kappa_{0 \text {,host }}$ value. Figure 8 shows the calculated Vs $-\kappa_{0}$ adjustment factors for both the median value and the upper and lower limits in our target $\kappa_{0}$ as a function of the period for each of the five GMPEs in the GMC model. Overall, we find that the calculated adjustment factors for PGA and the GMPEs vary between approximately 0.65 and 1.25 for the median target $\kappa_{0}$ value of $0.027 \mathrm{~s}$ (Fig. 8). Calculated values of the adjustments for a $\kappa_{0, \text { target }}$ value of $0.027 \mathrm{~s}$ for all five GMPEs converge to approximately 1.0 at longer periods. The adjustments for all three empirical GMPEs (Bindi et al. 2014; Boore et al. 2014; Cauzzi et al. 2015) have a similar form, with a peak at $0.05 \mathrm{~s}$ and values that decrease at longer periods. The maximum adjustment factor for Boore et al. (2014) and Bindi et al. (2014) is approximately 1.4-1.5, whereas the maximum adjustment factor is approximately 1.2 for Cauzzi et al. (2015). Applying these host-target adjustments will result in slight increases in the spectral response at periods less than $\sim 1 \mathrm{~s}$. This is consistent with the calculated values for the host $\kappa_{0}$ for these three GMPEs, which are all larger than those for the target $\kappa_{0}$ considering that the host and target Vs30 are relatively similar. We observe notable differences in the period dependent adjustments for the two stochastic GMPEs (Rietbrock et al. 2013; Atkinson and Boore 2006) with both of these resulting in a small decrease in the original spectral level at the shortest periods. This may be a result of differences in both elastic amplification and $\kappa_{0}$ for the host and target. Specifically, the adjustments for Atkinson and Boore (2006) are smaller than 1.0 at periods $<1.0 \mathrm{~s}$, resulting in a decrease in spectral response at these periods. The adjustment factors for Rietbrock et al. (2013) are also less than 1.0 for periods of $<0.08 \mathrm{~s}$, but are larger than 1.0 at longer periods, increasing to a peak at approximately $0.2 \mathrm{~s}$ before decreasing to around 1.0 at periods of more than $1.0 \mathrm{~s}$.

The calculated adjustments for the upper and lower target $\kappa_{0}$ allow us to assess the effect of epistemic uncertainty in our choice of target $\kappa_{0}$ on the results. The adjustments for the 
lower $\kappa_{0}$,target $v a l u e$ of $0.016 \mathrm{~s}$ are consistently larger than those for the $\kappa_{0 \text {,target }}$ of $0.027 \mathrm{~s}$, and are greater than 1.0 for all five GMPEs and most periods. Conversely, adjustments for the upper $\kappa_{0}$,target $v$ value of $0.047 \mathrm{~s}$ are smaller than 1.0 for all the GMPEs.

\subsection{Comparison between predicted and observed ground motion}

To assess whether the GMC model of Tromans et al. (2019) was an appropriate choice for the UK seismic hazard maps, we compare the $\mathrm{Vs}-\mathrm{K}_{0}$ adjusted ground motion predictions computed from ten GMPEs with the UK strong motion data. Besides the GMPEs used by Tromans et al. (2019) in Table 4, we selected also Abrahamson et al. (2014), Campbell and Bozorgnia (2014), Chiou and Youngs (2014), Akkar et al. (2014a), and Pezeshk et al. (2011). All these ten GMPEs pass the exclusion criteria of Bommer et al. (2010) and are considered to be applicable for the UK. We did not consider the GMPE of Yenier and Atkinson (2015) for SCRs because it does not provide the aleatory variability (i.e. sigma model). For this work, we use the stochastic model of Pezeshk et al. (2011) and Rietbrock et al. (2013) rather than their updated models (Pezeshk et al. 2018; Rietbrock and Edwards 2019) because the latter was not available when we started to test the existing GMPEs against the UK strong motion data in 2018.

The UK strong motion data consist of 377 recordings of PGA at Rjb up to $400 \mathrm{~km}$ from 35 small-to-moderate $\left(3.3 \leq \mathrm{M}_{\mathrm{w}} \leq 5.0\right)$ earthquakes that have occurred in the UK between January 1980 and August 2018. In the interests of brevity, we show the visual comparison of ground motion predictions for the GMPEs used in the GMC model and observed ground motions from five earthquakes (Fig. 9). The data from these five earthquakes are listed in Table 6. The ground motion predictions are computed for a rock site (Vs30=800 m/s) and a strike-slip faulting mechanism. In general, the agreement between predictions and observations is better for data recorded from small $\left(<3.9 \mathrm{M}_{\mathrm{w}}\right)$ earthquakes rather than from moderate earthquakes and the former fall clearly within one sigma from the median predictions of the GMPEs. Many GMPEs for active shallow crustal regions seem to underestimate the UK data, whereas the model of Atkinson and Boore (2006) seems to overpredict the UK data.

We apply the residual analysis, the log-likelihood (LLH) method of Scherbaum et al. (2009), and the Euclidian Distance-based Ranking (EDR) method of Kale and Akkar (2013) to make a more objective assessment of the suitability of a particular GMPE. The reader can refer to Mosca et al. (2020) for the full details of these analyses. The LLH function of Scherbaum et al. (2009) evaluates the performance of the GMPE for a particular ground motion dataset. The EDR approach results in three output parameters, MDE (Modified Euclidian distance), $\mathrm{k}^{0.5}$, and EDR (Kale and Akkar 2013). The first evaluates the effect of the standard deviation of the GMPE with the observed ground motion dataset. The parameter $\mathrm{k}^{0.5}$ evaluates the median prediction of the GMPE for the observed dataset. The overall effect of these two parameters is given by the EDR parameter. The results of these analyses are displayed in Fig. 10 for the ten selected, adjusted GMPEs. Among the four NGA (Next Generation Attenuation)-West2 GMPEs (Abrahamson et al. 2014; Boore et al. 2014; Campbell and Bozorgnia 2014; Chiou and Youngs 2014), which were derived using a similar dataset of recordings, the model of Abrahamson et al. (2014) seems to perform better than the others against the UK data. The GMPEs of Akkar et al. (2014a) and Bindi et al. (2014) were derived using recordings from earthquakes in Europe and the Middle East included in the RESORCE European strong-motion database (Akkar et al. 2014b). The statistical results indicate that 

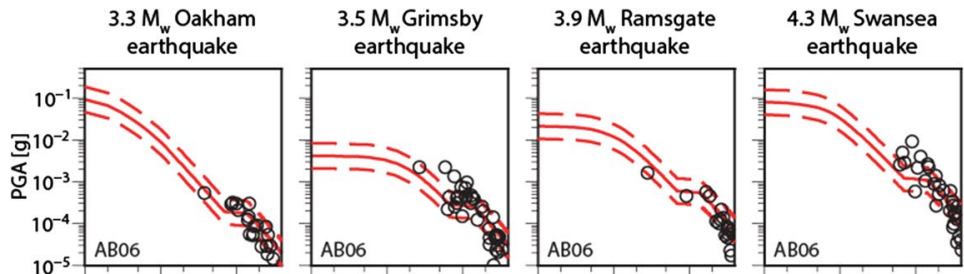

4.9 $\mathrm{M}_{\mathrm{w}}$ Market Rasen
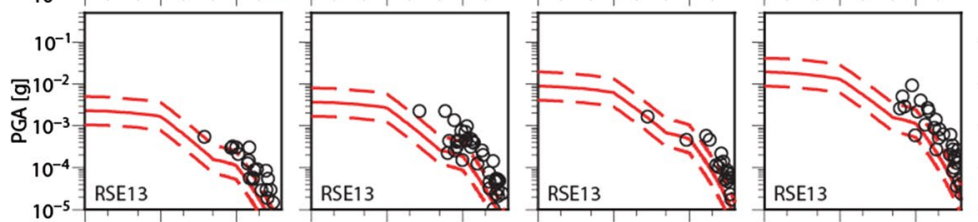

earthquake
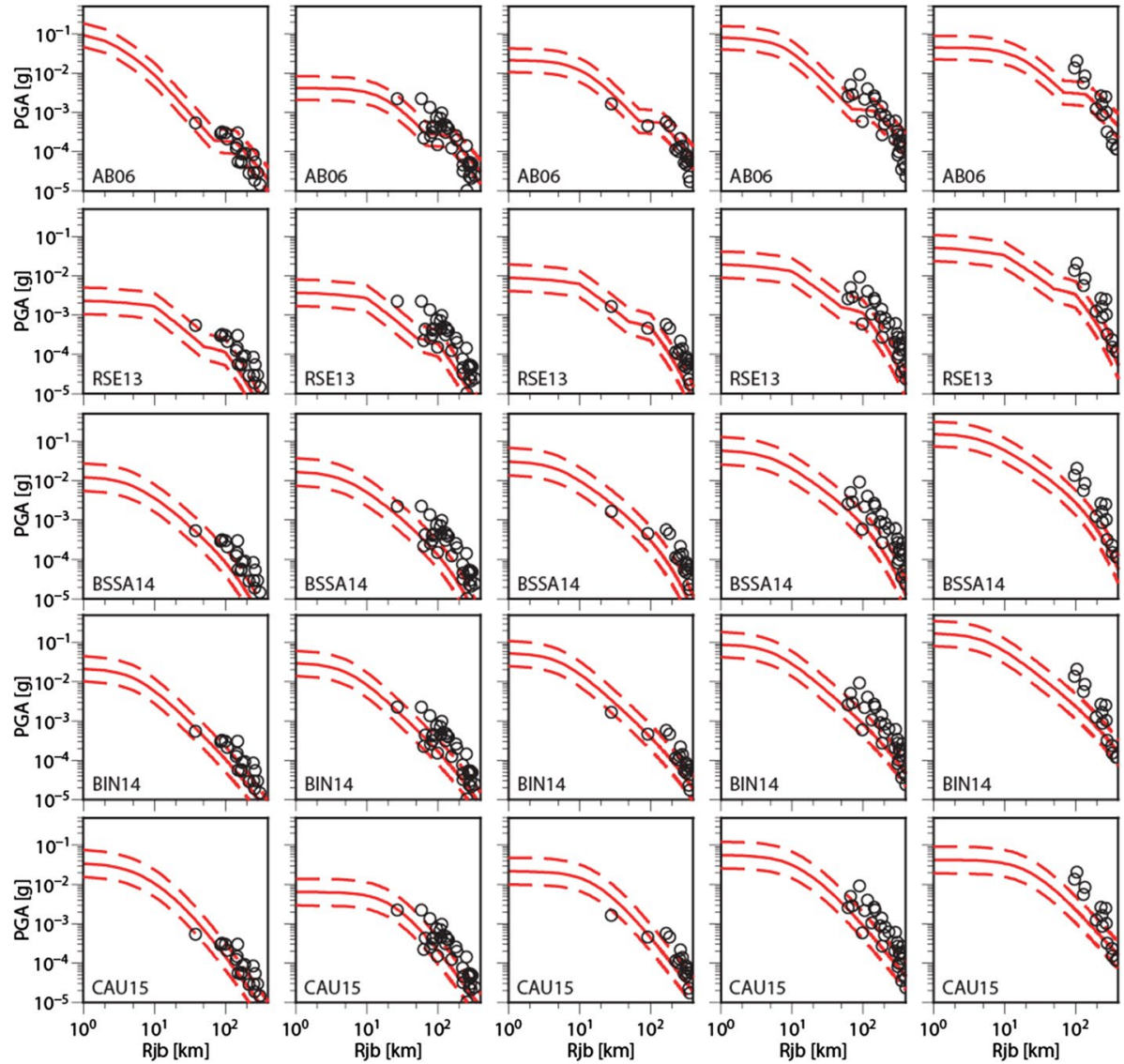

Fig. 9 Comparison of the Vs- $\kappa_{0}$ adjusted ground motion predictions using the GMPEs in Table 4 with PGA observations for the five UK earthquakes in Table 5. The strong motion data for PGA are expressed as the geometric mean of the two orthogonal horizontal components. The solid red lines describe the median prediction of the GMPEs, and the dashed red lines describe the median prediction \pm one sigma

Table 6 Earthquakes selected for the visual comparison between predicted and observed ground motions in Fig. 9

\begin{tabular}{llrlll}
\hline Date & Location & Depth $[\mathrm{km}]$ & $\mathrm{M}_{\mathrm{w}}$ & $\begin{array}{l}\text { Number of } \\
\text { recordings }\end{array}$ & Range of the PGA values \\
\hline $27 / 02 / 2008$ & Market Rasen & 18 & 4.9 & 15 & $1.2 \times 10^{-4} ; 1.4 \times 10^{-2}$ \\
$18 / 04 / 2014$ & Oakham & 3 & 3.3 & 23 & $4.8 \times 10^{-6} ; 5.4 \times 10^{-4}$ \\
$22 / 05 / 2015$ & Ramsgate & 12 & 3.9 & 18 & $5.8 \times 10^{-5} ; 1.7 \times 10^{-3}$ \\
$17 / 02 / 2018$ & Swansea & 8 & 4.3 & 31 & $2.4 \times 10^{-5} ; 5.1 \times 10^{-3}$ \\
$09 / 06 / 2018$ & Grimsby & 19 & 3.5 & 39 & $5.9 \times 10^{-6} ; 2.3 \times 10^{-3}$ \\
\hline
\end{tabular}



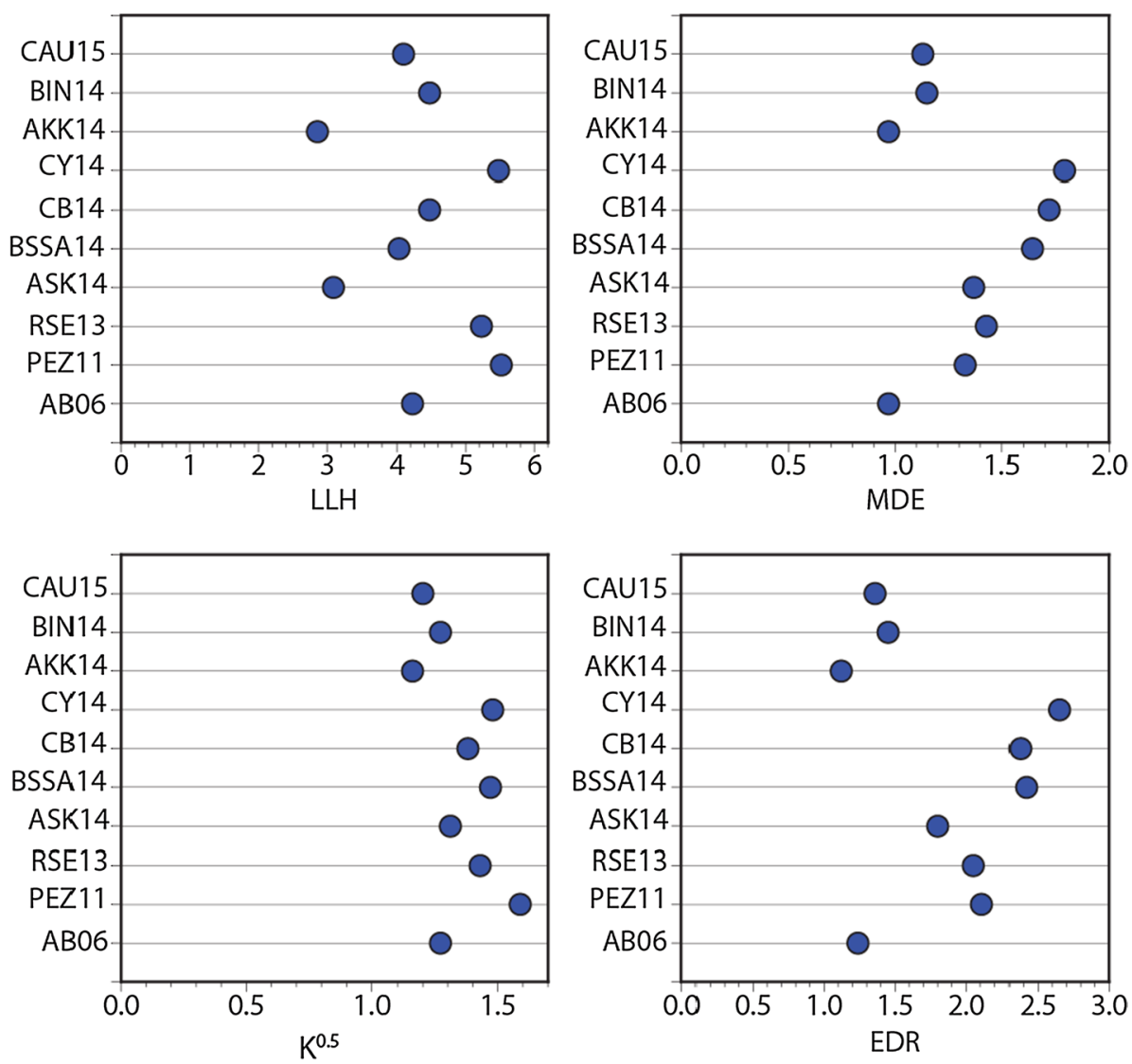

Fig. $10 \mathrm{LLH}, \mathrm{MDE}, \mathrm{k}^{0.5}$, and EDR values as a function of ten selected, adjusted GMPEs for PGA. GMPEs are abbreviated as follows: AB06=Atkinson and Boore (2006); PEZ11=Pezeshk et al. (2011); RSE13=Rietbrock et al. (2013); ASK14=Abrahamson et al. (2014); BSSA14= Boore et al. (2014); CB14=Campbell and Bozorgnia (2014); CY14=Chiou and Youngs (2014); AKK14=Akkar et al. (2014a); BIN14 = Bindi et al. (2014); CAU15 = Cauzzi et al. (2015)

the former predicts slightly better the UK strong motion data than the latter. The stochastic GMPE of Atkinson and Boore (2006) gets lower LLH and EDR values than the Pezeshk et al. (2011) GMPE. Both were derived for SCRs. The GMPEs of Rietbrock et al. (2013) and Cauzzi et al. (2015) were derived using recordings from the UK and worldwide with a large majority from Japan, respectively. Their LLH score and EDR values are in line with those computed for the other GMPEs. The overall performance of the 10 GMPEs for the same statistical parameter is relatively similar (between 3 and 5.8 for LLH, 1 and 2 for MDE, 1.2 and 1.5 for $\mathrm{k}^{0.5}$, and 1.1 and 2.7 for EDR) suggesting that the statistical methods are unable to assess the predictive model performance of the selected GMPEs for the strong motion dataset in the UK and provide only a qualitative indication of the GMPE performance. This is because this dataset consists of only weak motion data and does not contain recordings at short source-to-site distances to rank the GMPEs with greater resolution. This conclusion was also highlighted in Tromans et al. (2019). 
To select the suite of GMPEs to populate the ground motion logic tree, we made the following considerations. We prefer the GMPE of Boore et al. (2014) among the NGAWest 2 models because the functional form of this GMPE is relatively simpler than that of Abrahamson et al. (2014), Campbell and Bozorgnia (2014), Chiou and Youngs (2014), and does not contain some input parameters (e.g. depth-to-top of the rupture and depth to $\mathrm{Vs}=2.5 \mathrm{~km} / \mathrm{s}$ ), which are unknown in most of the regions in the world and thus are set to default values calibrated on earthquakes that occurred mainly in California. We select Bindi et al. (2014) over Akkar et al. (2014a) as this is used in two of the most recent site-specific PSHA studies in the UK (Tromans et al. 2019; Villani et al. 2019, 2020). We also select the model of Atkinson and Boore (2006) between the two models for SCRs. This is because the UK is an intraplate region with low levels of seismicity and we cannot rule out GMPEs for SCRs. However, the seismological properties of the crust under the UK (e.g. attenuation model) are more similar to active seismic regions such as Western North America than the stable regions such as Eastern North America. For this reason, we assign a low weight to the Atkinson and Boore (2006) model. To complete the suite of GMPEs for this work, we select also the GMPE of Rietbrock et al. (2013) and Cauzzi et al. (2015). The model of Rietbrock et al. (2013) has a lower weight because it is poorly constrained at short distances. Given these considerations, we adopt the GMC model of Tromans et al. (2019) for this work (Table 4). This model is also consistent with the recommendations for the definition of the GMC model in Villani et al. (2019) who suggest using one GMPE among Abrahamson et al. (2014), Boore et al. (2014), Campbell and Bozorgnia (2014), and Chiou and Youngs (2014), together with the GMPE of Bindi et al. (2014), Cauzzi et al. (2015), and the stochastic model of Rietbrock and Edwards (2019).

\section{Hazard results}

We calculate the hazard using Monte Carlo-based simulations to generate artificial catalogues by random sampling of the probability distributions in the SSC model (Musson 2000). Musson (2012c) and Mosca (2019) show that the Monte Carlo-based approach is compatible with a Cornell-McGuire type approach and provides the same output given the same initial model. The implementation of the individual GMPEs has been checked against the ground motion library in the OpenQuake (Pagani et al. 2014).

The minimum magnitude (Mmin) in a hazard calculation is defined as the threshold for potentially damaging earthquakes (e.g. Bommer and Crowley 2017). This parameter is usually defined between 4 and $5 \mathrm{M}_{\mathrm{w}}$ for PSHA. In MS07, Mmin was $4.5 \mathrm{M}_{\mathrm{w}}$, whereas here, we consider that $4.0 \mathrm{M}_{\mathrm{w}}$ is more appropriate because it includes the probability that the impulsive nature of small earthquakes and their high-frequency content could be potentially causing damage. The impact of such small but damaging earthquakes is clearly shown by the $4.0 \mathrm{Mw}$ Folkestone earthquake in 2007, which was relatively small, but caused significant non-structural damage and also some light structural damage in very few locations (Sargeant et al. 2008). The choice of a minimum magnitude of $4.0 \mathrm{Mw}$ is consistent with previous PSHA for nuclear sites in the UK (e.g. Villani et al. 2020). However, we note that another recent PSHA for a nuclear site in the UK (Tromans et al. 2019) use a minimum magnitude of $4.5 \mathrm{M}_{\mathrm{w}}$. Recent NSHMs in low seismicity regions have a minimum magnitude between 4.3 and 4.5 Mw (Wiemer et al. 2016; Grünthal et al. 2018; Drouet et al. 2020). 


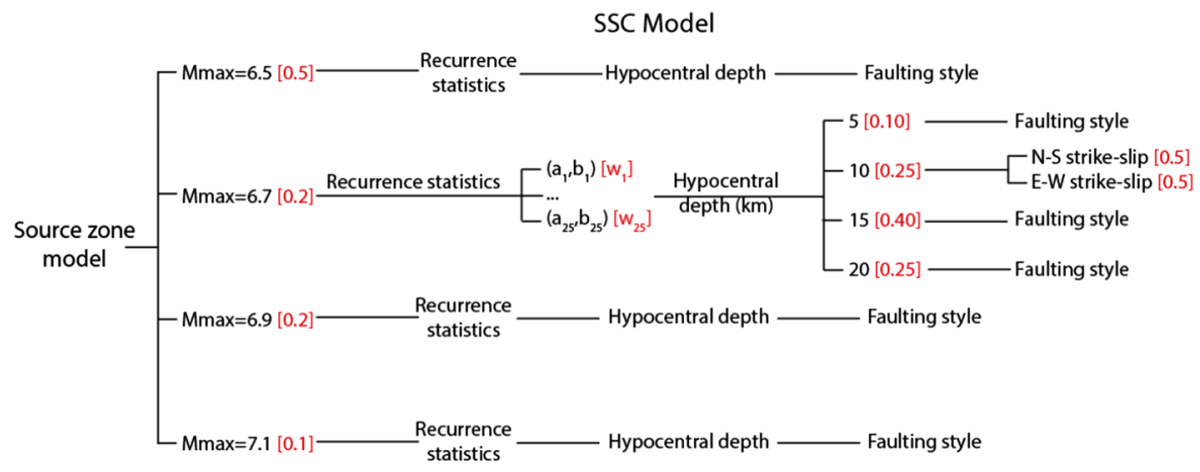

GMC Model

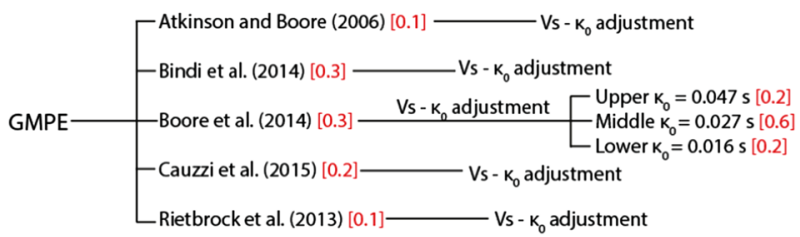

Fig. 11 SSC and GMC logic tree for the NSHM for the UK

The SSC and GMC models used in the hazard computation are shown in Fig. 11. Using the SSC model (top panel in Fig. 11), we generate 100,000 synthetic earthquake catalogues, each 100 years long. This gives a total of 10,000,000 years of simulated data, which is sufficient to resolve the hazard accurately for return periods up to 10,000 years (Musson 2000). Each simulated catalogue represents a version of what could occur. The ground motion is computed for each earthquake in the simulated catalogues using the GMC model (bottom panel in Fig. 11). Following Strasser et al. (2008), we did not truncate the distribution representing the aleatory uncertainty of ground motions. By sorting the ground motion results in order of decreasing severity, it is possible to identify ground motions associated with different frequencies of exceedance (Musson 2000).

The hazard calculations were carried out for the region between $49^{\circ} \mathrm{N}$ and $61^{\circ} \mathrm{N}$ and $8.5^{\circ} \mathrm{W}-2^{\circ} \mathrm{E}$ for a grid of 4141 points spaced $0.125^{\circ}$ in latitude and $0.25^{\circ}$ in longitude $\left(\sim 12 \mathrm{~km}\right.$ in both directions). We computed the hazard for PGA, $\mathrm{SA}_{0.2 \mathrm{~s}}$, and $\mathrm{SA}_{1.0 \mathrm{~s}}$ with $5 \%$ damping for $\mathrm{Vs} 30=800 \mathrm{~m} / \mathrm{s}$ and return periods of $95,475,1100$, and 2475 years. The resulting hazard maps for return periods of 475 years ( $10 \%$ annual frequency of exceedance in 50 years) and 2475 years ( $2 \%$ annual frequency of exceedance in 50 years) are shown in Figs. 12 and 13, respectively. The maps for 95 and 1100 years are available at http://www. earthquakes.bgs.ac.uk/hazard/UKhazard.html.

For 475 years, PGA is less than $0.04 \mathrm{~g}$ for most of the UK, except for North Wales and the England-Wales border region where the hazard reaches around $0.09 \mathrm{~g}$ and $0.05 \mathrm{~g}$, respectively (left panel of Fig. 12). A similar spatial variation is observed at $0.2 \mathrm{~s}$ but the effects are more pronounced (central panel of Fig. 12). These areas of relatively higher hazard are due to source zones with higher levels of seismic activity (i.e. MMCW, MMCR and NORM). At $1.0 \mathrm{~s}$, accelerations are smaller than $0.02 \mathrm{~g}$ (right panel of Fig. 12) but show less variation across the UK. For a return period of 


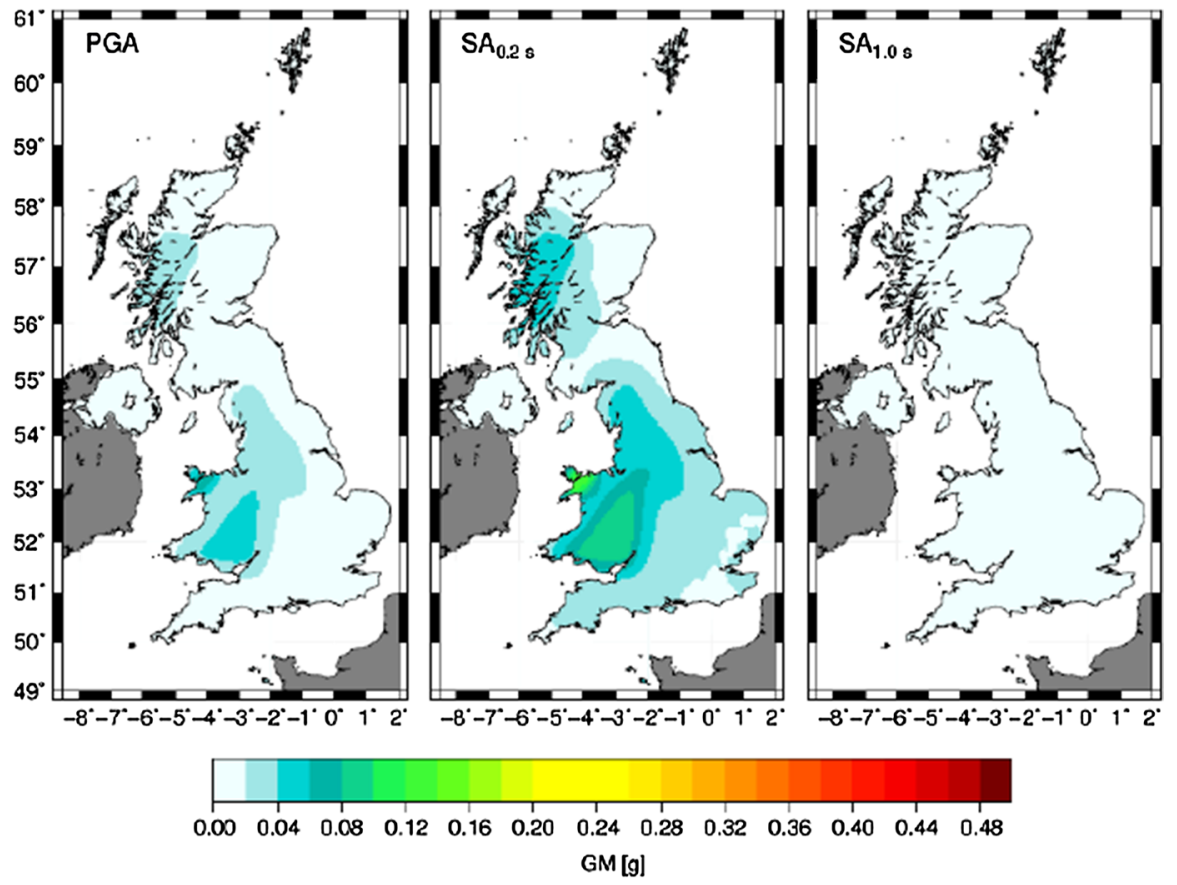

Fig. 12 Hazard map for PGA, $\mathrm{SA}_{0.2 \mathrm{~s}}$, and $\mathrm{SA}_{1.0 \mathrm{~s}}$ at the 475 year return period
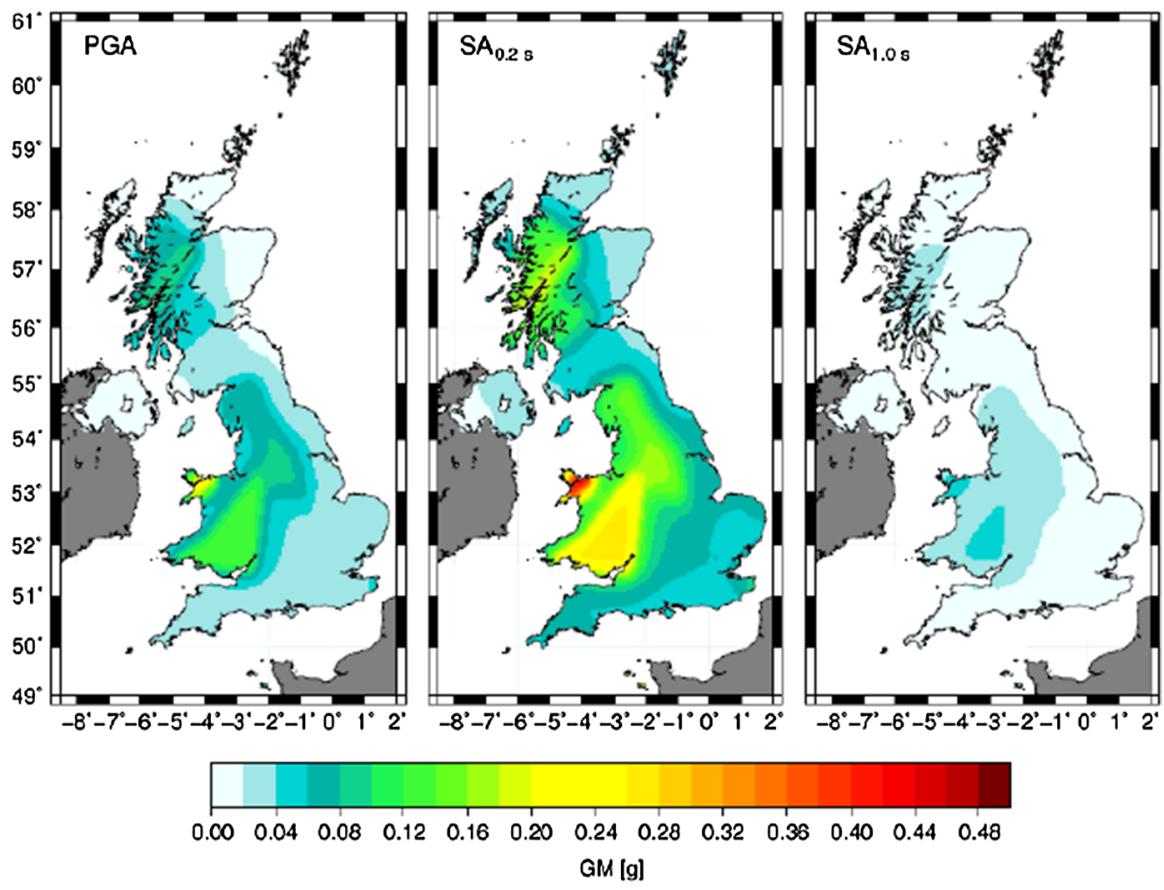

Fig. 13 Hazard map for PGA, $\mathrm{SA}_{0.2 \mathrm{~s}}$, and $\mathrm{SA}_{1.0 \mathrm{~s}}$ at the 2475 year return period 
2475 years, the Channel Islands, North Wales, the England-Wales border region through to North Central England, the Lake District and north-west Scotland are the areas of highest hazard for PGA and $\mathrm{SA}_{0.2 \mathrm{~s}}$ (Fig. 13). The highest hazard values $(0.25 \mathrm{~g}$ for PGA and $0.47 \mathrm{~g}$ for $\mathrm{SA}_{0.2 \mathrm{~s}}$ ) are observed around the region of Snowdonia, in North Wales.

\subsection{Site-specific hazard results}

We have computed hazard curves, uniform hazard spectra (UHS), and the disaggregation analysis for four sites (i.e. Cardiff, Dover, Edinburgh, and London) that are located in regions of different levels of hazard across the UK (see yellow stars in Fig. 1b). Figure 14 shows the hazard curves for PGA, SA $0.2 \mathrm{~s}, \mathrm{SA}_{1.0 \mathrm{~s}}$, and the UHS for 475 and 2475 year return period for the four sites.

We disaggregated the hazard results in terms of magnitude, Rjb, $\varepsilon$ (the number of standard deviations above or below the median ground motion prediction) and the originating source zone to determine which earthquake(s) control the hazard for the key return periods. Using a Monte Carlo-based PSHA, this simply means searching the synthetic catalogues derived from the SSC model for ground motions that are greater than or equal to the design acceleration (plus or minus a small tolerance factor that is $0.001 \mathrm{~g}$ here; Musson 2000). In the interests of brevity, we present the results for PGA and the four sites (Figs. 15, 16, 17 and 18).

Disaggregating by zone for Cardiff, 86-92\% of ground motions for PGA are greater than or equal to the design value $(0.033 \mathrm{~g}$ for 475 years and $0.100 \mathrm{~g}$ for 2475 years) from the second population of earthquakes $\left(4.5-7.1 \mathrm{M}_{\mathrm{w}}\right)$ in MMCW. Disaggregating the hazard by magnitude, distance and $\varepsilon$ for PGA (Fig. 15), we observe that for both $475 \mathrm{yr}$ and $2475 \mathrm{yr}$, the greatest contribution to the hazard comes from relatively small earthquakes of around 4.5-4.7 $\mathrm{M}_{\mathrm{w}}$ at relatively short distances $(<20 \mathrm{~km})$. Zones in south-eastern Britain and northern France region control the hazard at the Dover site with by far the biggest contribution coming from zone DOVE. This is also clear by disaggregating the hazard for the Dover site in terms of magnitude, distance and $\varepsilon$ (Figs. 16). For PGA, there is a single pronounced peak at 4.0-4.1 $\mathrm{M}_{\mathrm{w}}$ and distances of 5-15 km for $475 \mathrm{yr}$ and $2475 \mathrm{yr}$. For the site in Edinburgh, the largest contributions to the hazard are from zones SC34, SC78 and PENN and a broader range of earthquakes contributes to the PGA hazard (distances of $0-150 \mathrm{~km}$ and magnitudes of 5-6 $\mathrm{M}_{\mathrm{w}}$ ) although there is a peak at $4.3-4.5 \mathrm{Mw}$ and $35-45 \mathrm{~km}$ for $475 \mathrm{yr}$ and $4.5-4.7 \mathrm{M}_{\mathrm{w}}$ and $15-25 \mathrm{~km}$ for $2475 \mathrm{yr}$ (Fig. 17). Finally, for the London site, zones in southern Britain dominate the hazard as would be expected although the zone MMCW2 also makes a relatively large contribution. The hazard at this site is dominated by relatively small earthquakes $\left(4.3-4.5 \mathrm{M}_{\mathrm{w}}\right)$ at short distances (less than $40 \mathrm{~km}$ ) for PGA (Fig. 18).

Overall, the disaggregation results for PGA indicate that moderate $\left(<5.0 \mathrm{M}_{\mathrm{w}}\right)$ earthquakes at short distances dominate the hazard in the UK.

\subsection{Sensitivity analysis}

We have carried out a sensitivity analysis to investigate the impact of different decisions taken to develop the SSC and GMC models on the seismic hazard for various sites across the UK. We tested the following features of the NSHM: 

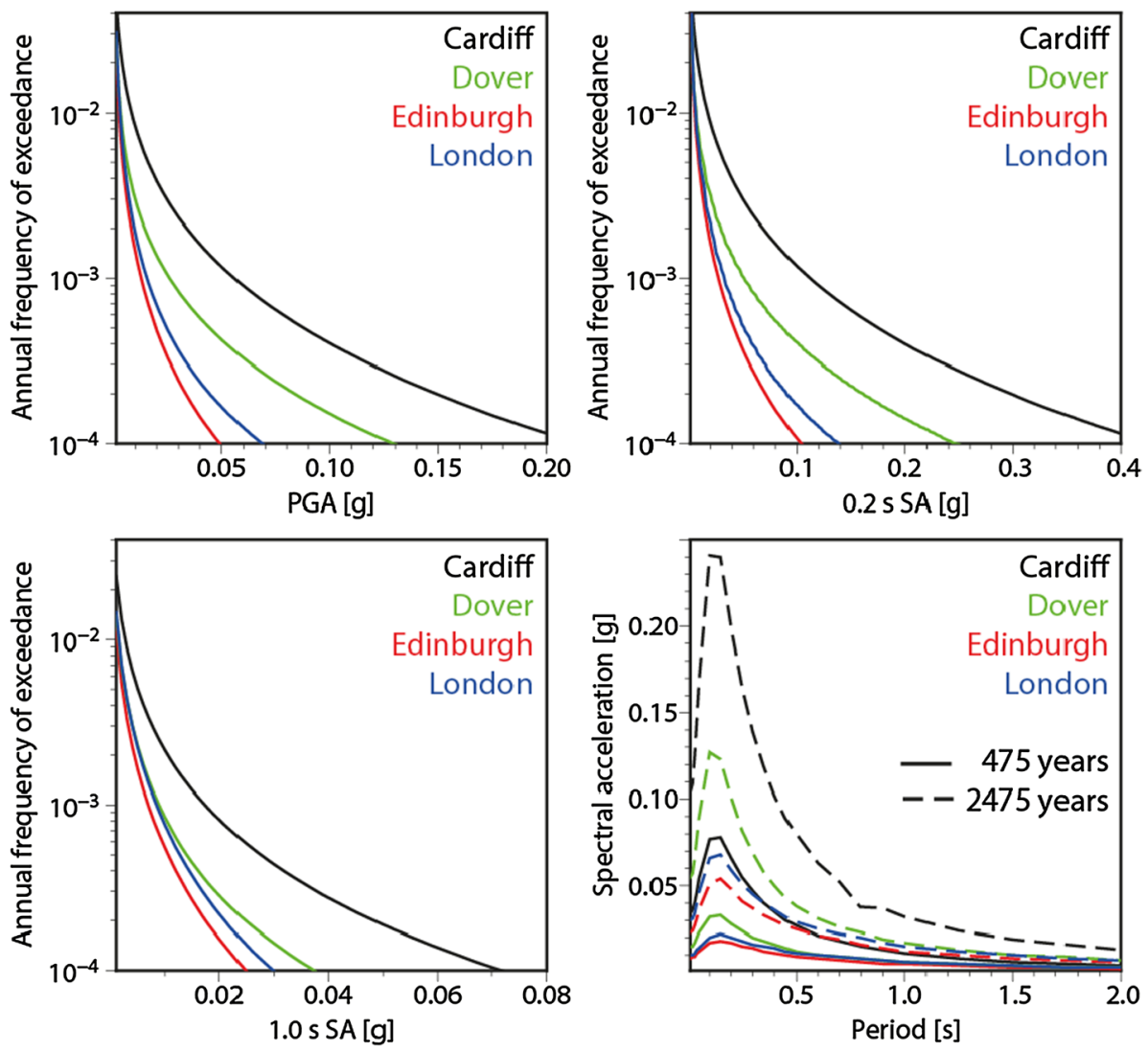

Fig. $14 \mathrm{PGA}, \mathrm{SA}_{0.2 \mathrm{~s}}, \mathrm{SA}_{1.0}$ hazard curves, and UHS for return periods of $475 \mathrm{yr}$ and $2475 \mathrm{yr}$ for a site in Cardiff, Dover, Edinburgh, and London (see Fig. 1b for the location of the sites)

- The minimum magnitude of $4.5 \mathrm{M}_{\mathrm{w}}$ (rather than 4.0);

- The maximum magnitude distribution used in MS07;

- The assessment of catalogue completeness used in MS07;

- The SSC model of MS07 with a minimum magnitude of $4.0 \mathrm{M}_{\mathrm{w}}$;

- The individual GMPEs included in the GMC model;

- The effect of excluding the Vs- $\kappa_{0}$ adjustments for the GMPEs in the GMC model.

Here, we show the results for Cardiff, South Wales, a site located in a region of higher hazard in the UK. The reader can refer to Mosca et al. (2020) for the sensitivity analysis for the sites in Dover, Edinburgh, and London. The results are expressed in terms of the percentage difference between the values of PGA for the individual tests and the values in Fig. 14 at return periods of $475 \mathrm{yr}$ and $2475 \mathrm{yr}$ (Fig. 19). A percentage difference less than $\pm 5 \%$ corresponds to a hazard variation between -0.001 and $0.001 \mathrm{~g}$; whereas a percentage difference $< \pm 20 \%$ results in a variation in the hazard between -0.02 and $0.02 \mathrm{~g}$. The effect of using a minimum magnitude of $4.5 \mathrm{M}_{\mathrm{w}}$ (rather than 4.0$)$ is very small $(<3 \%)$ for the three ground motion parameters and the two return periods because the hazard is dominated by earthquakes of $>4.5 \mathrm{M}_{\mathrm{w}}$ and 


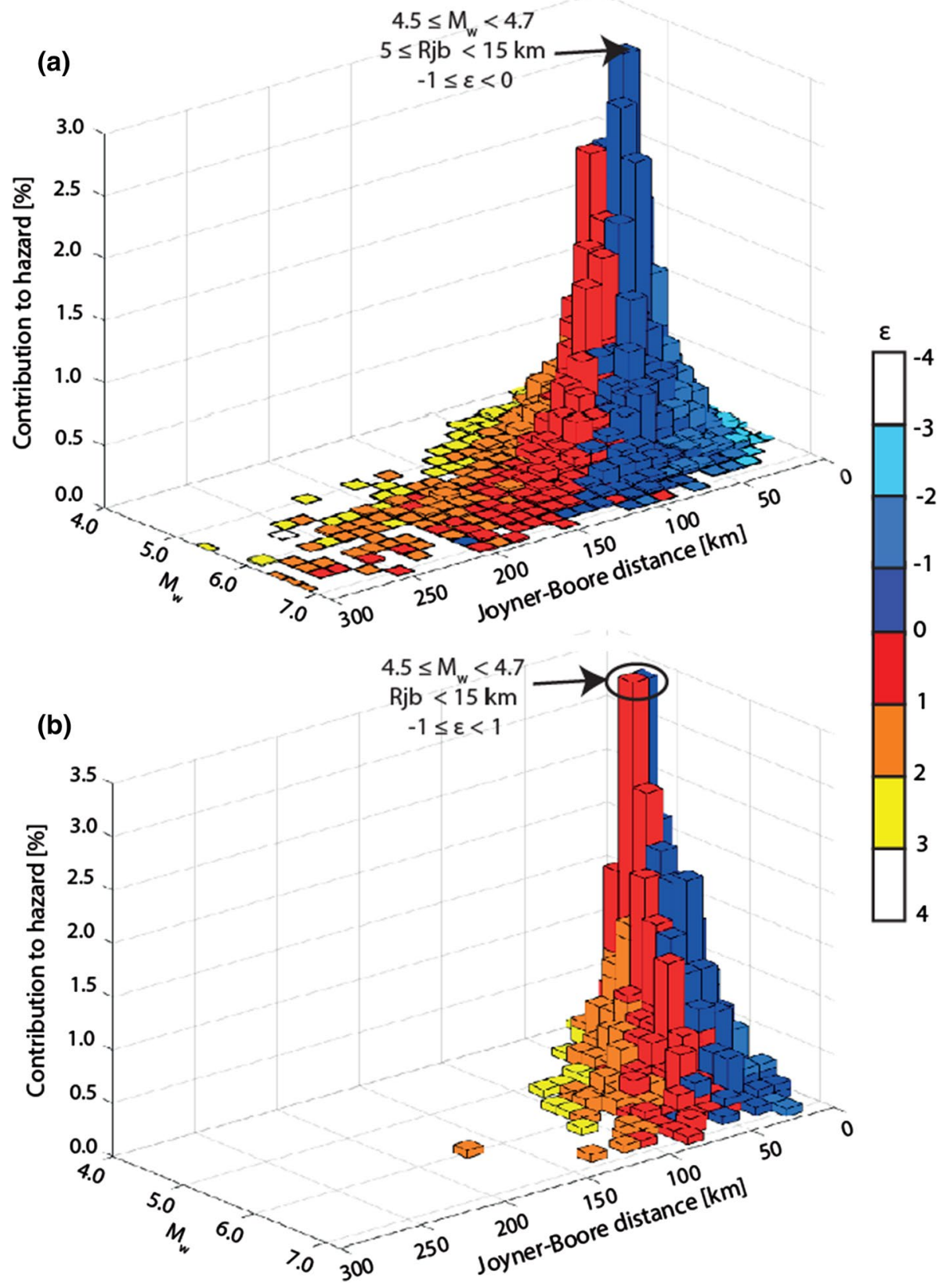

Fig. 15 Disaggregation of the PGA hazard for the Cardiff site by magnitude $\left(\mathrm{M}_{\mathrm{w}}\right)$, Joyner-Boore distance and epsilon $(\varepsilon)$ for a $475 \mathrm{yr}(0.033 \mathrm{~g})$ and b $2475 \mathrm{yr}(0.100 \mathrm{~g})$. Numbers in brackets are the design values used for the disaggregation 


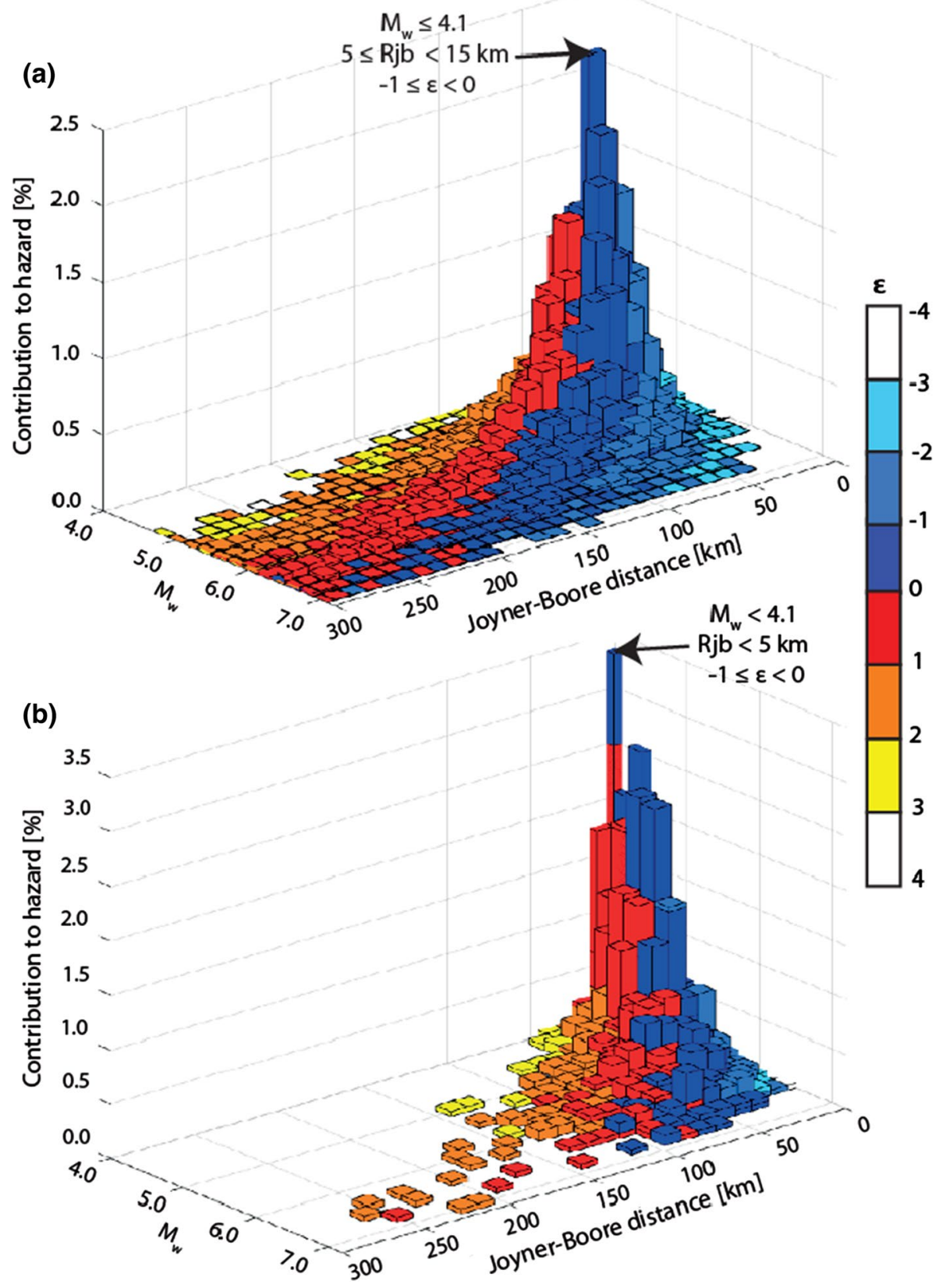

Fig. 16 Disaggregation of the PGA hazard for the Dover site by magnitude $\left(\mathrm{M}_{\mathrm{w}}\right)$, Joyner-Boore distance and epsilon $(\varepsilon)$ for a $475 \mathrm{yr}(0.014 \mathrm{~g})$ and $\mathbf{b} 2475 \mathrm{yr}(0.052 \mathrm{~g})$. Numbers in brackets are the design values used for the disaggregation 


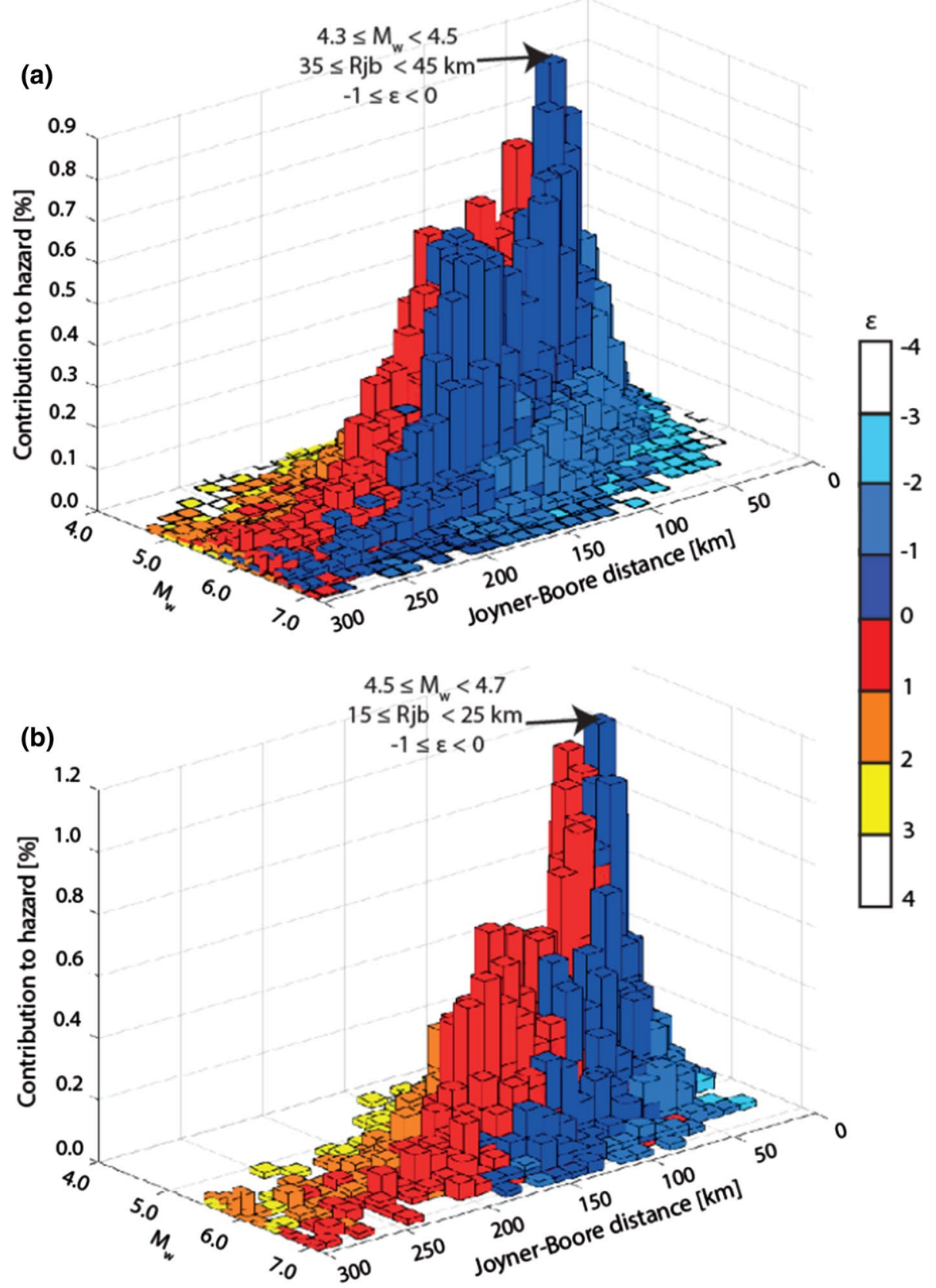

Fig. 17 Disaggregation of the PGA hazard for the Edinburgh site by magnitude $\left(\mathrm{M}_{\mathrm{w}}\right)$, Joyner-Boore distance and epsilon $(\varepsilon)$ for a $475 \mathrm{yr}(0.008 \mathrm{~g})$ and b $2475 \mathrm{yr}(0.023 \mathrm{~g})$. Numbers in brackets are the design values used for the disaggregation 


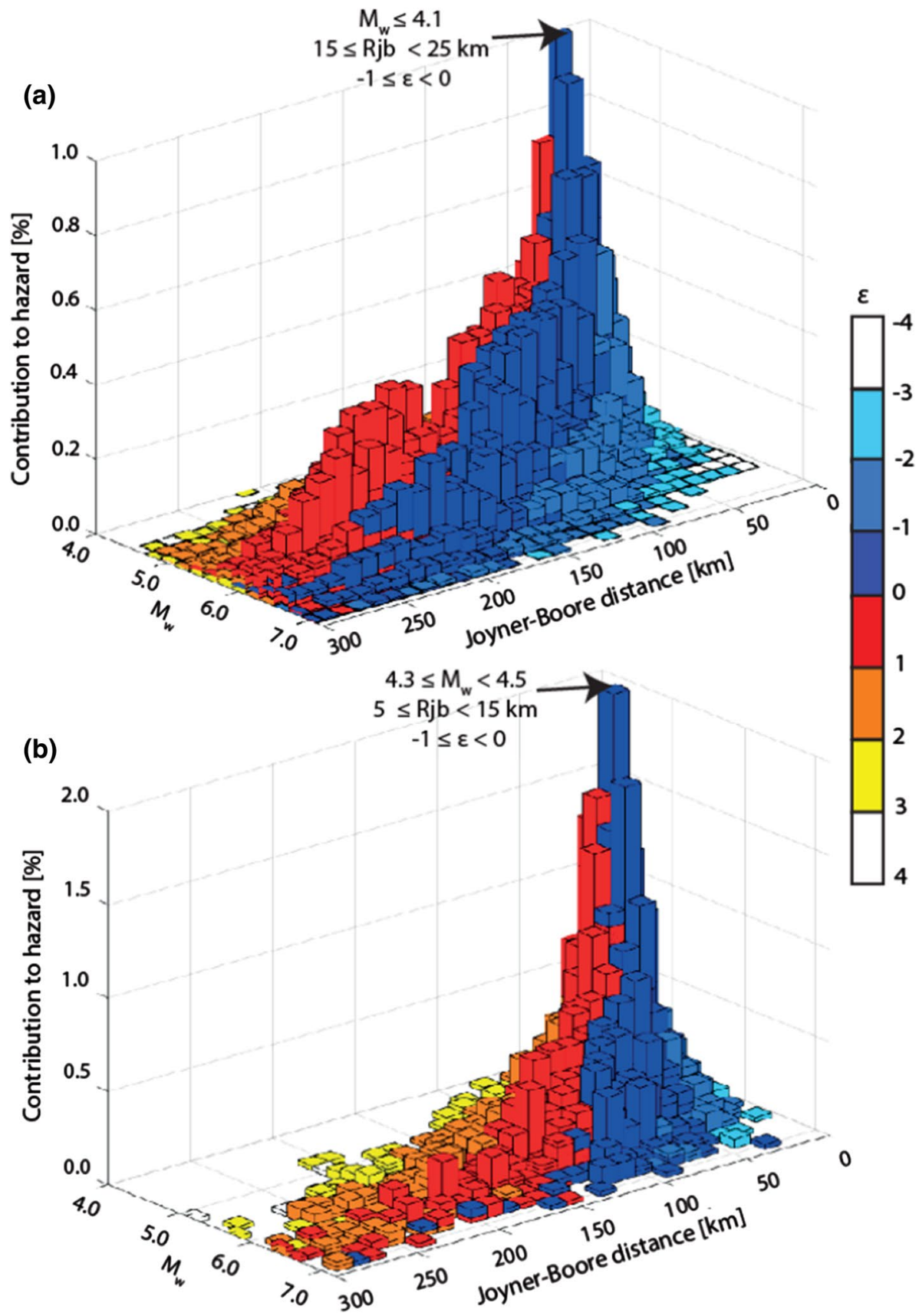

Fig. 18 Disaggregation of the PGA hazard for the London site by magnitude $\left(\mathrm{M}_{\mathrm{w}}\right)$, Joyner-Boore distance and epsilon $(\varepsilon)$ for $\mathbf{a} 475 \mathrm{yr}(0.010 \mathrm{~g})$ and b $2475 \mathrm{yr}(0.029 \mathrm{~g})$. Numbers in brackets are the design values used for the disaggregation 
therefore using a minimum magnitude of 4.0 or $4.5 \mathrm{M}_{\mathrm{w}}$ does not produce any significant difference. Using the maximum magnitude distribution in MS07 results in an overall decrease in the hazard which is more pronounced for $\mathrm{SA}_{1.0 \mathrm{~s}}$ since larger earthquakes make a greater contribution to long period spectral accelerations. Using the assessment of catalogue completeness in MS07 results in a relatively small $(<6 \%)$ increase in PGA, $\mathrm{SA}_{0.2 \mathrm{~s}}$ and $\mathrm{SA}_{1.0 \mathrm{~s}}$. If the SSC model of MS07 is used, there is a small decrease $(<10 \%)$ for PGA and $\mathrm{SA}_{0.2 \mathrm{~s}}$ and a significant decrease for $\mathrm{SA}_{1.0 \mathrm{~s}}$ (between 40 and $50 \%$ ). This reduction in the hazard is because the seismicity in South Wales, where Cardiff is located, was modelled as a separate zone in MS07, whereas in the 2020 SSC model the seismicity is amalgamated in a larger zone (i.e. MMCW). If we exclude the Vs $-\kappa_{0}$ adjustments for the GMPEs in the GMC model, the hazard decreases by up to $20 \%$. Finally, when we use the individual GMPEs in the GMC model, the variation of the hazard is between $-50 \%$ and $20 \%$ with the largest variation associated with Atkinson and Boore (2006) and Rietbrock et al. (2013). These two GMPEs have the lowest weight in the GMC model (see Sect. 5).

\subsection{Comparison with previous studies}

We compare the hazard maps produced in this study with the maps developed by MS07, the ESHM13 maps of Woessner et al. (2015), and the national hazard maps for France and Germany.

Both this study and MS07 find that the hazard in the UK is relatively low compared to more active regions. To facilitate this comparison, we have calculated the absolute difference between the ground motion parameters at each point for which the maps have been calculated. The differences between the results of the two studies are shown for PGA and the return periods of $475 \mathrm{yr}$ and $2475 \mathrm{yr}$ (Fig. 20). These differences are explained by the different components of PSHA used to build the two NSHMs. Regions in blue in South Wales and the English Midlands reflect a reduction in PGA due to the different SSC model used in MS07 and in this study. For example, the seismicity in South Wales was modelled as a separate zone in MS07, whereas it is amalgamated into a large zone (MMCW) in the 2020 NSHM. Furthermore, the zone for South Wales in MS07 accounted for the second population of earthquakes with 4.5-7.1 $\mathrm{M}_{\mathrm{w}}$. Regions in red reflect an increase in PGA, especially in North Wales, North Central England and north-west Scotland (Fig. 20), due to many factors, especially the SSC model and the GMC model. A general increase in PGA across the UK from the 2007 maps to the 2020 maps is due to the higher Mmax distribution, which determine an increase in hazard up to $15 \%$ (Fig. 19), and the GMC model, including the Vs- $\kappa_{0}$ adjustments, in the 2020 NSHM. Furthermore, the PGA values in Central Wales are higher in the 2020 maps than in MS07 because the bi-partite FMD is applied for MMCW. The increase in hazard in southern England in the 2020 maps is due to the influence of the zones NORM and PASC. The spatial distribution of the absolute difference between the 2007 and 2020 studies is similar for 475 and 2475 years but it is slightly higher for the latter than for the former. The most noticeable feature for the 2475 year return period is the decrease in PGA over Comrie in central Scotland (right-hand side plot in Fig. 20). This is because the small source zone used in MS07 to account for intense earthquake swarms in this area in historical time is not included in our model and the seismicity is now accounted for in the larger zone SC34 resulting in a decrease in hazard around Comrie. One important difference between the MS07 and the 2020 NSHM is the inclusion of zones NORM 


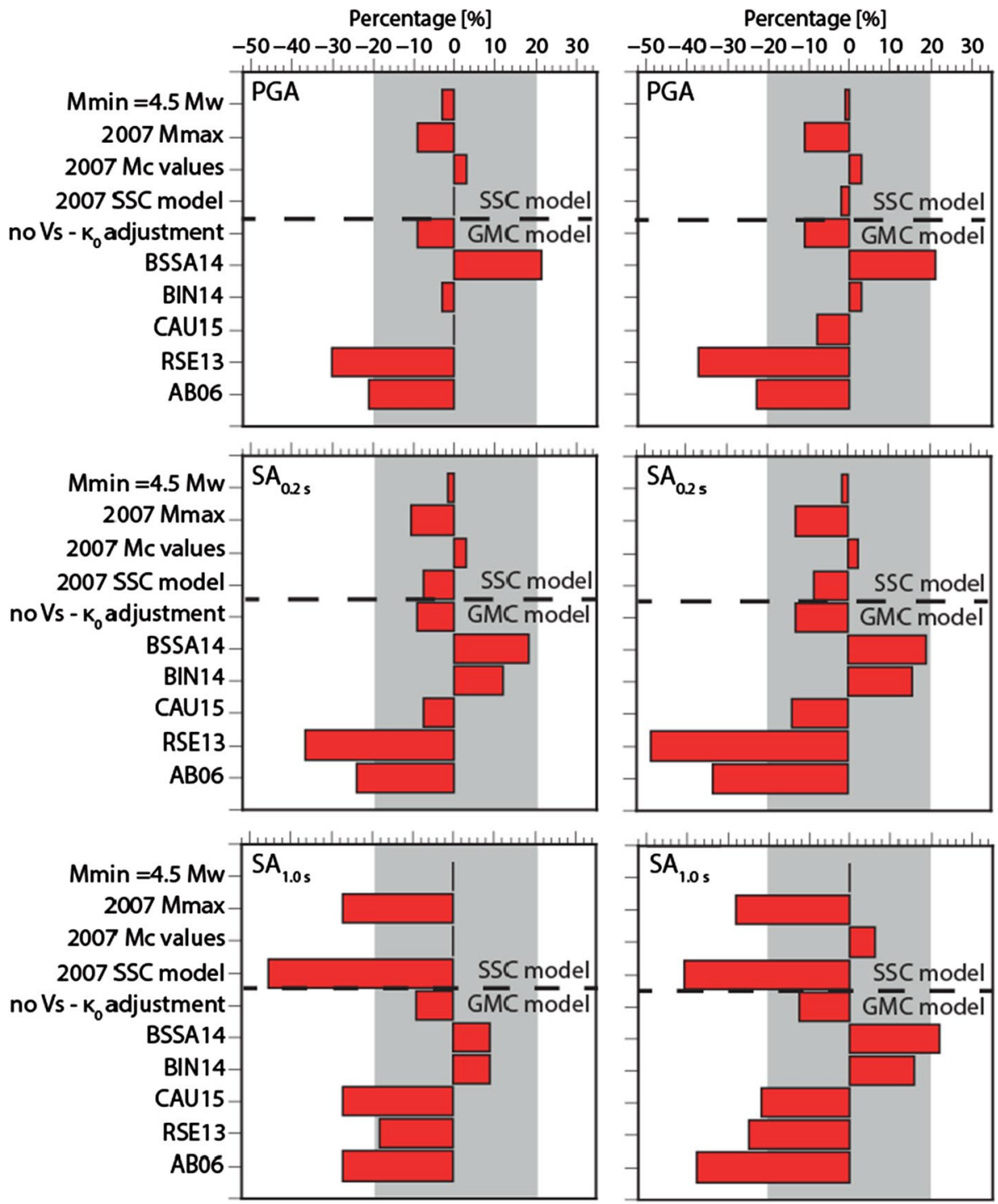

Fig. 19 Results of the sensitivity analysis for PGA, $\mathrm{SA}_{0.2 \mathrm{~s}}$ and $\mathrm{SA}_{1.0 \mathrm{~s}}$ at a site located in Cardiff as the percentage difference between the results computed using the hazard model and the modified model used for each test. Results are for 475 years (first column) and 2475 years (second column). The grey area describes the variation in hazard of less than $\pm 20 \%$

and PASC to account for seismicity in northern France and Belgium (see Fig. 5a). Although the zones have little influence on the hazard in southern England, they do result in higher hazard for the Channel Islands compared to MS07.

The comparison between the 2020 seismic hazard maps for the UK and the ESHM13 maps developed by the SHARE project (Woessner et al. 2015) are shown in Figs. 21-22 

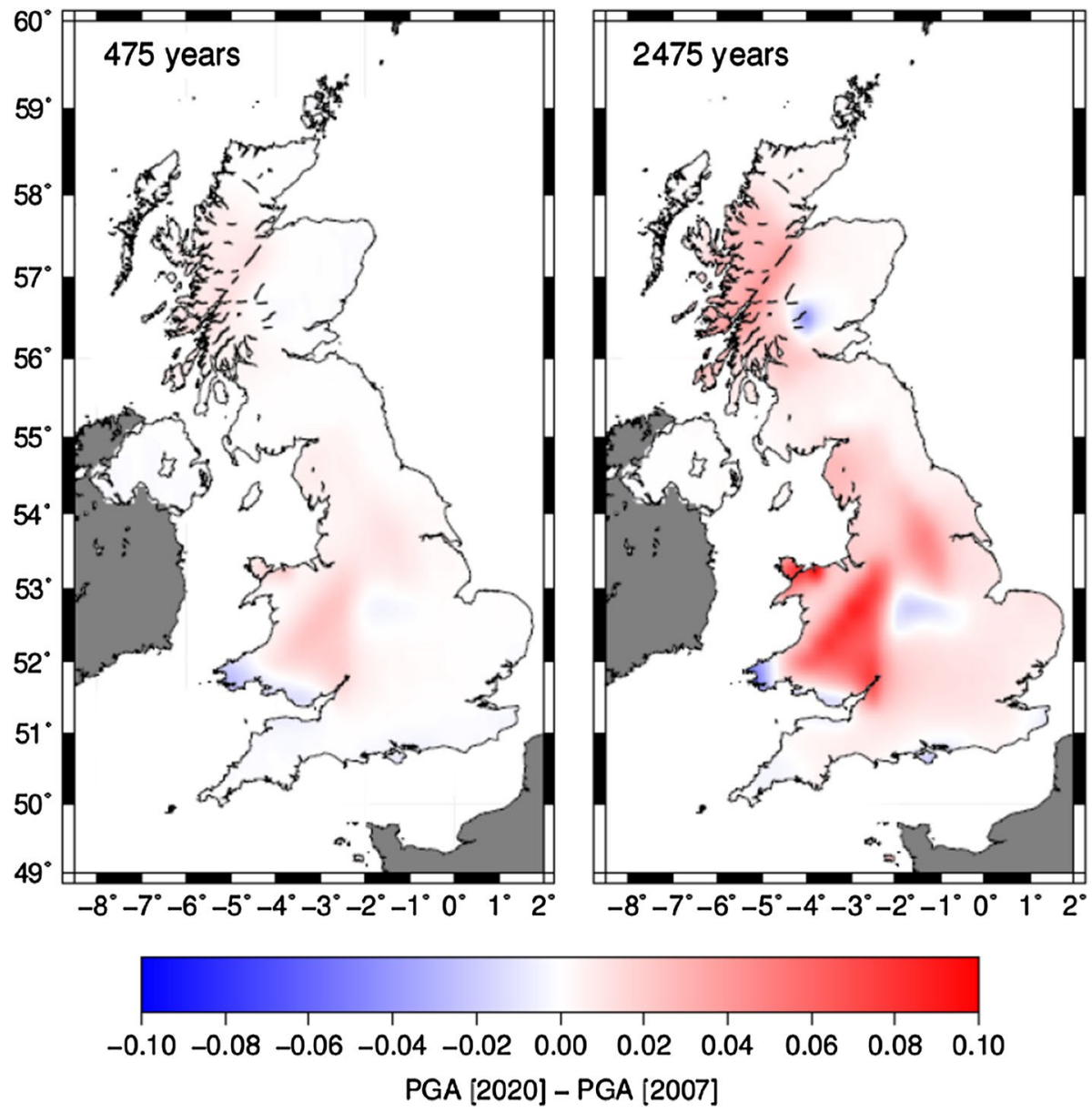

Fig. 20 Maps showing the absolute difference between the results of this study (PGA[2020]) and MS07 (PGA[2007]) for the return periods of 475 and 2475 years

for $475 \mathrm{yr}$ and $2475 \mathrm{yr}$, respectively. Note that the absolute difference in hazard between the 2020 maps and the ESHM13 maps is larger than that between the 2007 and 2020 national maps. For $475 \mathrm{yr}$, the differences between the results of the two studies are relatively small for PGA and slightly higher at a spectral period of $0.2 \mathrm{~s}$ (Fig. 21). The greatest differences are in the English Midlands $(-0.02 \mathrm{~g}$ for PGA and $-0.05 \mathrm{~g}$ for $\left.\mathrm{SA}_{0.2 \mathrm{~s}}\right)$ and around the Menai Strait $\left(-0.02 \mathrm{~g}\right.$ for PGA and -0.05 for $\left.\mathrm{SA}_{0.2 \mathrm{~s}}\right)$. For $\mathrm{SA}_{0.2 \mathrm{~s}}$, there a general tendency across England for ESHM13 to give higher values (up to $0.02 \mathrm{~g}$ higher). At $1.0 \mathrm{~s}$ spectral period, the two maps are very similar and the absolute differences between the two studies are smaller than $0.01 \mathrm{~g}$. For $2475 \mathrm{yr}$, the spatial distribution of the absolute differences between the 2020 NSHM for the UK and ESHM13 is similar to that for $475 \mathrm{yr}$ but the magnitude of the absolute differences is higher (Fig. 22). The difference between the two studies is not surprising given that most elements of the models used in the hazard assessments are different. 


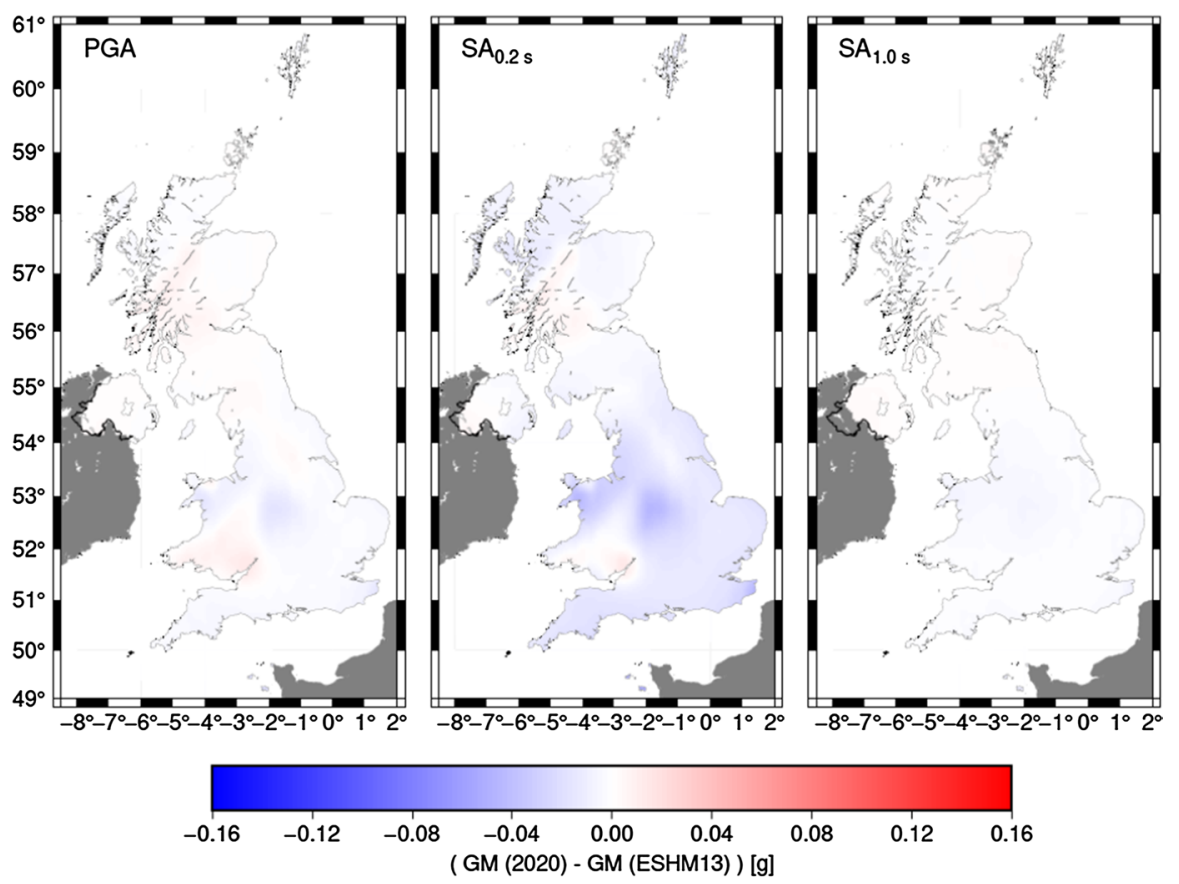

Fig. 21 Maps showing the absolute difference between the results of this study (GM[2020]) and Woessner et al. (2015) (GM[ESHM13]) for PGA, $\mathrm{SA}_{0.2 \mathrm{~s}}$ and $\mathrm{SA}_{1.0 \mathrm{~s}}$ and the return period of $475 \mathrm{yr}$

We also compared our results with the recently published maps for France and Germany to check whether the hazard levels in the UK are comparable to those of other European countries that are classified as "low seismicity" regions. The PGA hazard for northern and central France is smaller than $0.04 \mathrm{~g}$ and increases up to $0.25 \mathrm{~g}$ in the Alps and the Pyrenees for a return period of 475 years (see Fig. 20 in Drouet et al. 2020). For 475 years, the national hazard map for Germany (left panel in Fig. 24 in Grünthal et al. 2018) shows high hazard ( $>0.3 \mathrm{~g})$ in the regions along the river Rhine and the border with the Austrian Alps; whereas most of northern and central Germany has PGA values of $<0.04 \mathrm{~g}$. Although the revised NSHM for the UK was considered independently from those for France and Germany, we find that the hazard values in the UK are largely consistent with the low hazard in northern France and Germany, providing some additional confidence in the robustness of our results.

\section{Discussion}

We have developed an updated NSHM for the UK that attempts to account for both limitations in data and our understanding of the earthquake process in this region. Three areas require more detailed consideration in future studies: the inclusion of robust uncertainties in the earthquake catalogue; and, epistemic uncertainty in both the SSC and GMC models.

The BGS earthquake catalogue is not homogeneously and comprehensively assessed for the uncertainty in the epicentral location and the magnitude of the historical and 


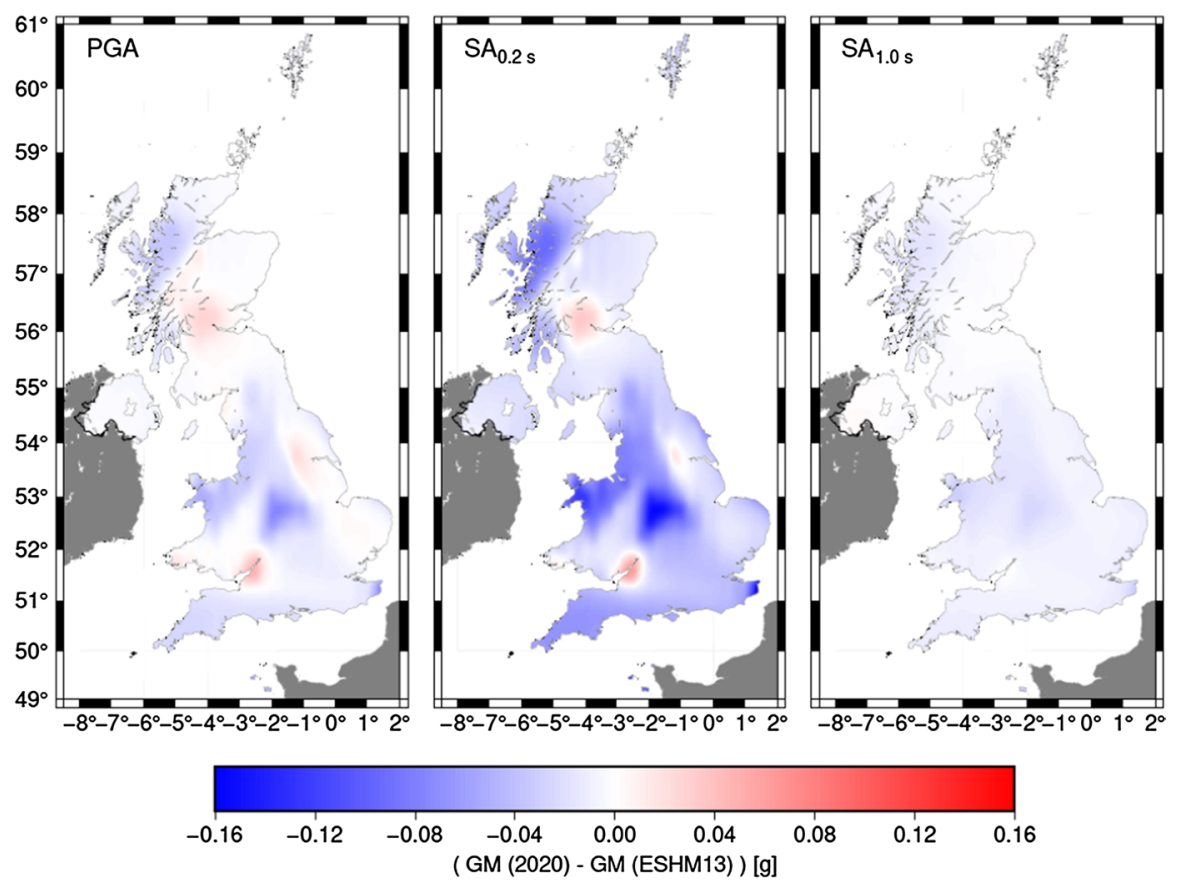

Fig. 22 Maps showing the absolute difference between the results of this study (GM[2020]) and Woessner et al. (2015) (GM[ESHM13]) for PGA, $\mathrm{SA}_{0.2 \mathrm{~s}}$ and $\mathrm{SA}_{1.0 \mathrm{~s}}$ and the return period of 2475 years

instrumental earthquakes. The former will have a strong impact on the delineation of the seismic source zone model; the latter will strongly influence the calculation of the rate of seismicity across the UK. Uncertainties in either location or magnitude are not currently available for historical earthquakes in the catalogue. Further work is needed to robustly estimate these from all the available macroseismic data. Simpler measures of uncertainty could be estimated from either the age of the event or the number of macroseismic data points. The former is based on the assumption that the oldest events have the largest uncertainties, which may not be correct. Alternatively, all events could be given the same uncertainty, which is unrealistic, but it would have allowed the introduction of some element of uncertainty. Similarly, uncertainties for some, but not all instrumentally recorded events. These were calculated differently in different time periods. Again, this requires systematic analysis to resolve it and it is beyond the scope of this paper. We also note that the uncertainty in location and magnitude can be strongly coupled, particularly for historical events where the uncertainty in location is high. For example, the more distant the location from a single macroseismic observation the larger the felt area and the greater the magnitude. This problem is particularly critical for earthquakes that occur offshore. In such cases, Musson (1994) uses the location that is closest to shore but still consistent with the available data. The conversion of magnitudes from one scale to another, in this case ML to $\mathrm{M}_{\mathrm{w}}$, is an additional source of uncertainty that also needs to be accounted for. Similarly, local magnitudes (ML) for historical earthquakes in the catalogue were estimated from the felt area, again resulting in additional uncertainty. A careful assessment of the different components of the 
magnitude uncertainty for the individual events is required to avoid introducing bias in the estimation of the seismicity rates (EPRI 2012; Musson 2012b).

The SSC model used in this study consists of a single source zone model and excludes other potential source zone models based on different interpretations of the mapped tectonic structures, large scale deformation, regional stress field, and observed seismicity in the UK. Similarly, previous hazard assessments for the UK also only considered a single source zone model (Musson and Winter 1996; Musson and Sargeant 2007). In comparison, other recent NSHMs for Germany and France used more than one source zone model. The use of a single source model is a limitation of the 2020 UK NSHM as it can be argued that the epistemic uncertainties in our understanding of the tectonics and driving forces for earthquake activity are not adequately captured in the model. Further research is required to develop alternative source zone models by involving more specialists from different disciplines to interpret geological, seismological, geophysical and geodetic data in the UK and propose different models that would capture the centre, body, and range of technically defensible interpretations.

Recent national seismic hazard studies for Switzerland (Wiemer et al. 2016), Germany (Grünthal et al. 2018), and France (Drouet et al. 2020) also included zoneless (zone-free, smoothed) models (see Beauval et al. 2006; Zechar and Jordan 2010 for more details) in the SSC model. These zoneless source models typically have lower weights than the zonal source models as they rely on observed catalogues with limited temporal duration. However, the zoneless approach requires robust estimates of the uncertainties in earthquake locations and magnitudes for all earthquakes, neither of which are available in the British catalogue. Future work should focus on the zoneless source model for the UK as an alternative branch in the source model logic tree if when the magnitude and location uncertainties are characterised for the entire catalogue.

Finally, the small British strong motion dataset, which consists of weak motion recordings only and does not contain recordings at near-source distances, represents a big challenge in the selection of the GMPEs for the GMC model and limits which methods (between the multi-GMPE approach and the backbone approach) can be implemented. Although this challenge requires ongoing monitoring in the UK, one way to overcome the limited amount of ground motion recordings is to augment the dataset with synthetic data generated from stochastic simulations of the ground motion (e.g. Edwards and Fäh 2013; Drouet and Cotton 2015). Furthermore, the strong motion recordings in the UK are not associated with Vs30 because most of the monitoring stations are uncharacterised in terms of local site conditions. An investigation of the variability in the shear wave velocity in the near-surface will help to better constrain the GMC model. For the Vs $-\kappa_{0}$ adjustments to the GMPEs in the GMC model, we used a single generic shear wave velocity profile for the UK target. However, it is possible that multiple profiles with the same Vs 30 of $800 \mathrm{~m} / \mathrm{s}$ could lead to different amplification functions. Further work is needed to better assess the suitability of our generic target profile. During this project, new ground motion models have been published (e.g. Pezeshk et al. 2018; Rietbrock and Edwards 2019) making some of our selected models in the ground motion logic tree superseded. However, we preferred not to adopt the most recent GMPE before it has been subject to extensive testing and rely on consolidated models, in which strengths and deficiencies are well informed.

It is important to highlight that the level of details of PSHA at the regional scale should be uniform across the country and is not driven by the specific site of interest as it happens for site-specific PSHA (e.g. Gerstenberger et al. 2020). This means that a point in a seismic hazard map is a first-order approximation at a national scale and the decisions to construct the seismic hazard model are not taken with respect to a specific site (Musson and Sargeant 
2007). Furthermore, NSHMs usually do not consider the hazard for long ( $\geq 10,000$ years) return periods that are important for highly critical structures, such as dams and LNG power plants. To compute the hazard for such long return periods, the effects of distant large earthquakes and the occurrence of earthquakes at very long recurrence intervals should be accounted for. The former requires computing the hazard at longer spectral periods, and the latter requires a detailed geological investigation in the area within $300 \mathrm{~km}$ from the site. In this context, the NSHM and the accompanying hazard maps are not a substitute for a site-specific assessment if one is required.

\section{Conclusions}

We have presented an updated NSHM for the UK with accompanying hazard maps for PGA and spectral acceleration at different return periods that have been derived using objective and reproducible data-driven methodologies, especially for the analysis of the earthquake catalogue.

The NSHM incorporates updated datasets and some of the advances made in PSHA and ground motion modelling since 2007, such as the use of the Vs- $\kappa_{0}$ adjustments in the GMC model. For the first time, the maps have been computed for a larger area, which includes also the Shetland Islands, than in MS07 and are provided for $\mathrm{SA}_{0.2 \mathrm{~s}}$ and $\mathrm{SA}_{1.0 \mathrm{~s}}$ to meet the requirements of Eurocode 8 and the drafting of a National Annex for the revised edition of Eurocode 8: Design of structures for earthquake resistance. The 2020 hazard maps confirm that seismic hazard in the UK is generally relatively low and comparable to the low seismicity regions in France and Germany.

The main challenge in building seismic hazard maps is that parameters, such as maximum magnitude, cannot be reliably estimated at present even in areas of high seismicity. This problem is exacerbated in low seismicity areas because the earthquake catalogue may not reflect the long-term hazard and the limited amount of ground motion observations do not allow us to test the results from the NSHM. Although this challenge requires ongoing monitoring in low seismicity regions, a way to strengthen the NSHM is to focus on better capturing the uncertainties in every component of the hazard model such as considering alternative branches in the source model logic tree and quantifying the uncertainty in the earthquake parameters.

Acknowledgements We are very grateful to Guillermo Aldama-Bustos, John Douglas, Ben Edwards, Peter Stafford, Fleur Strasser and Iain Tromans whose insightful comments and informal advice helped improve the NSHM. We are also very grateful for the support and input of the members of the BSI National Committee B/525/8 Structures in Seismic Regions and Edmund Booth, Ziggy Lubkowski and Tim Allmark in particular, and members of the ONR Review Panel for their helpful reviews of the NSHM. From the BGS, we thank Davie Galloway for his assistance in developing and checking the earthquake catalogue; Margarita Segou for useful discussions on the catalogue analysis; Maarten Krabbendam and Graham Leslie for their guidance on matters relating to the seismo-tectonics of the UK; Richard Luckett for the internal review of the manuscript. The authors would also like to thank the reviewers for their comments which helped improve the quality of this article.

\section{Declarations}

Conflict of interest This work was funded by the British Geological Survey and the Institution of Civil Engineers. The authors declare that they have no competing interest. The FORTRAN code for the hazard calculations, M3C, is available upon request. All of the input data, the components of the 2020 NSHM for the UK, 
and the output files described in this article are freely available from www.earthquakes.bgs.ac.uk. The plots were made using the Generic Mapping Tools version 6.1.1 (Wessel et al. 2019).

Open Access This article is licensed under a Creative Commons Attribution 4.0 International License, which permits use, sharing, adaptation, distribution and reproduction in any medium or format, as long as you give appropriate credit to the original author(s) and the source, provide a link to the Creative Commons licence, and indicate if changes were made. The images or other third party material in this article are included in the article's Creative Commons licence, unless indicated otherwise in a credit line to the material. If material is not included in the article's Creative Commons licence and your intended use is not permitted by statutory regulation or exceeds the permitted use, you will need to obtain permission directly from the copyright holder. To view a copy of this licence, visit http://creativecommons.org/licenses/by/4.0/.

\section{References}

Abrahamson NA, Silva WJ, Kamai R (2014) Summary of the ASK14 ground motion relation for active crustal regions. Earthq Spectra 30(3):1025-1055

Akkar S, Sandikkaya MA, Bommer JJ (2014a) Empirical ground motion models for point- and extended-source crustal earthquake scenarios in Europe and the Middle East. Bull Earthq Eng 12(1):359-387

Akkar S, Sandıkkaya MA, Senyurt M, Sisi AA, Ay BÖ, Traversa P, Douglas J, Cotton F, Luzi L, Hernandez B, Godey S (2014b) Reference database for seismic ground-motion in Europe (RESORCE). Bull Earthq Eng 12(1):311-339

Al Atik L, Kottke A, Abrahamson NA, Hollernback J (2014) Kappa (к) scaling of ground-motion prediction equations using an inverse random vibration theory approach. Bull Seismol Soc Am 104(1):336-346

Allen T, Griffin J, Leonard M, Clark D, Ghasemi H (2020) The 2018 National Seismic Hazard Assessment of Australia: quantifying hazard changes and model uncertainties. Earthq Spectra. https://doi.org/10. 1193/031319EQS057M

Amante C, Eakins B (2009) ETOPO1 1Arc-Minute global relief model: procedures, data resources and analysis. TNOAA Technical Memorandum NESDIS NGDC-24, 19 pp

Arup (1993). Earthquake hazard and risk in the UK. Report prepared for the Department of the Environment, pp 315

Atkinson GM, Boore DM (2006) Earthquake ground motion prediction equations for eastern North America. Bull Seismol Soc Am 96(6):2181-2205

Atkinson GM, Boore DM (2011) Modifications to existing ground-motion prediction equations in light of new data. Bull Seismol Soc Am 10(3):1121-1135

Atkinson GM, Bommer JJ, Abrahamson NA (2014) Alternative approaches to modelling epistemic uncertainty in ground motions in probabilistic seismic hazard analysis. Seismol Res Lett 85(6):1141-1144

Baptie B (2010) Seismogenesis and state of stress in the UK. Tectonophysics 482(1-4):150-159

Beauval C, Scotti O, Bonilla F (2006) The role of seismicity models in probabilistic seismic hazard estimation: comparison of a zoning and a smoothing approach. Geophys J Int 165(2):584-595

Bindi D, Massa M, Luzi L, Ameri G, Pacor F, Puglia R, Augiera P (2014) Pan-European ground-motion prediction equations for the average horizontal component of PGA, PGV, and 5\%-damped PSA at spectral periods up to $3.0 \mathrm{~s}$ using the RESORCE dataset. Bull Earthq Eng 12(1):391-430

BIS (2013) Nuclear industrial strategy: government and industry in partnership—The UK's nuclear future. BIS/13/627. Department for Business, Innovation and Skills, London, United Kingdom

Bluck BJ, Gibbons W, Ingham JK (1992). Terranes. In Cope JC, Ingham JK, Rawson PF (Eds), Atlas of Palaeogeography and Lithofacies. Geological Society London, Memoirs 13:1-4

Bolt BA, Abrahamson NA (2003) Estimation of strong seismic ground motions. In: Lee WHK, Kanamori $\mathrm{H}$, Jennings PC, Kisslinger C (eds) International handbook of earthquake and engineering seismology. Academic Press, San Diego, pp 983-1001

Bommer JJ, Abrahamson NA (2006) Why do modern probabilistic seismic hazard analyses lead to increased hazard estimates? Bull Seismol Soc Am 96(6):1967-1977

Bommer JJ, Scherbaum F (2008) The use and misuse of logic trees in probabilistic seismic hazard analysis. Earthq Spectra 24(4):997-1009

Bommer JJ, Crowley H (2017) The purpose and definition of the minimum magnitude limit in PSHA calculations. Seismol Res Lett 88:1097-1106 
Bommer JJ, Douglas J, Scherbaum F, Cotton F, Bungum H, Fäh D (2010) On the selection of groundmotion prediction equations for seismic hazard analysis. Seismol Res Lett 81:783-793

Boore DM (2003) Simulation of ground motion using the stochastic method. Pure Appl Geophys 160:635-676

Boore DM, Joyner WB (1997) Site amplifications for generic rock sites. Bull Seismol Soc Am 87:327-341

Boore DM, Stewart JP, Seyhan E, Atkinson GM (2014) NGA West 2 equations for predicting PGA, PGV, and 5\%-damped PSA for shallow crustal earthquakes. Earthq Spectra 30(3):1057-1085

Booth DC, Bott JDJ, O'Mongain AM (2001) The UK seismic velocity model for earthquake location-a baseline review. British Geological Survey Internal Report, IR/01/188, United Kingdom

Booth ED, Skipp B, Watt P (2008) Establishing the need for seismic design in the UK. Research Enabling Fund, Report ICE-02, Issue 2, 31/01/2008, Institution of Civil Engineers, United Kingdom

BS NA EN 1998-1 (2008) UK National Annex to Eurocode 8: Design of structures for earthquake resistance. BSI British Standards, London, United Kingdom

Budnitz RJ, Apostolakis G, Boore DM, Cluff LS, Coppersmith KJ, Cornell CA, Morris PA (1997). Recommendations for Probabilistic Seismic Hazard Analysis: Guidance on the Uncertainty and Use of Experts. Senior Seismic Hazard Analysis Committee, U.S. Nuclear Regulatory Commission, NUREG/CR-6372, Washington, DC

Burkhard M, Grünthal G (2009) Seismic source zone characterization for the seismic hazard assessment project PEGASOS by the Expert Group 2 (EG1b). Swiss J Geosci 102:149-188

Burton PW, Neilson G (1980) Annual catalogues of British earthquakes recorded on LOWNET (19671978). Seismol Bull 7, Institute of Geological Sciences, HMSO

Camelbeeck T, Vanneste K, Alexandre P, Verbeeck K, Petermans T, Rosset P, Everaerts M, Warnant R, Van Camp M (2007). Relevance of active faulting and seismicity studies to assessments of long-term earthquake activity and maximum magnitude in intraplate northwest Europe, between the Lower Rhine Embayment and the North Sea. In Stein S, Mazzotti S (Eds) Continental Intraplate Earthquakes: Science, Hazard, and Policy Issues. Geol S Am S 425:193-224.

Campbell KW, Bozorgnia Y (2014) NGA-West 2 ground motion model for the average horizontal components of PGA, PGV, and 5\%-damped linear acceleration response spectra. Earthq Spectra 30(3):1087-1115

Cao AM, Gao SS (2002) Temporal variation of seismic b-values beneath northeastern Japan island arc. Geophys Res Lett. https://doi.org/10.1029/2001GL013775

Cauzzi C, Faccioli E, Vanini M, Bianchini A (2015) Updated predictive equations for broadband (0.01-10s) horizontal response spectra and peak ground motions, based on a global dataset of digital acceleration records. Bull Earthq Eng 13:1587-1612

CEN (2004) Eurocode 8: Design of structures for earthquake resistance part 1: general rules, seismic actions and rules for buildings, European Norm. European Committee for Standardization, Brussels, Belgium

Chadwick RA, Pharaoh TC, Williamson JP, Musson RMW (1996) Seismotectonics of the UK. British Geological Survey Technical Report, WA/96/3C, United Kingdom

Chiou B, Youngs RR (2014) Update of the Chiou and Youngs NGA model for the average horizontal component of peak ground motion and response spectra. Earthq Spectra 30(3):1117-1153

Coppersmith K, Bommer J (2012) Use of the SSHAC methodology within regulated environments: costeffective application for seismic characterization at multiple sites. Nucl Eng Des 245:233-240

Cornell CA, Vanmarcke EH (1969) The major influences on seismic risk. In: Proc. 4th World Conf Earthquake Eng, Santiago, Chile

Cotton F, Scherbaum F, Bommer JJ, Bungum H (2006) Criteria for selecting and adjusting ground-motion models for specific target regions: application to Central Europe and rock sites. J Seismol 10:137-156

Crampin S, Jacob AWB, Miller A, Neilson G (1970) The LOWNET radio-linked seismometer network in Scotland. Geophys J Royal Astron Soc 21:207-216

Delavaud E, Scherbaum F, Kühn N, Allen T (2012) Testing the global applicability of ground motion prediction equations for active shallow crustal regions. Bull Seismol Soc Am 102(2):707-721

Douglas J, Edwards B (2016) Recent and future developments in earthquake ground motion estimation. Earth-Sci Rev 160:203-219

Douglas J (2018) Capturing geographically-varying uncertainty in earthquake ground-motion models or what we think we know may change. In Pitilakis K (Ed) Recent advances in earthquake engineering in Europe. 46:153-181

Drouet S, Cotton F (2015) Regional stochastic GMPEs in low-seismicity areas: scaling and aleatory variability analysis_-application to the French Alps. Bull Seismol Soc Am 105(4):1883-1902

Drouet S, Ameri G, Le Dortz K, Secanell R, Senfaute G (2020) A probabilistic seismic hazard map for the metropolitan France. Bull Earthq Eng. https://doi.org/10.1007/s10518-020-900790-7 
Edwards B, Fäh D (2013) A stochastic ground-motion model for Switzerland. Bull Seismol Soc Am 103:78-98

EPRI (2012) Technical report: Central and Eastern United States seismic source characterization for nuclear facilities. Electric Power Research Institute, Palo Alto, U.S. Nuclear Regulatory Commission, U.S. Department of Energy

Fäh D, Giardini D, Kästli P, Deichmann N, Gisler M, Schwarz-Zanetti G, Alvarez-Rubio S, Sellami S, Edwards B, Allmann B, Bethmann F, Wössner J, Gassner-Stamm G, Fritsche S, Eberhard D (2011) ECOS-09 earthquake catalogue of Switzerland release 2011 report and database, Report SED/ RISK/R/001/20110417

Frankel A (1995) Mapping seismic hazard in the Central and Eastern United States. Seismol Res Lett 66(4):8-21

Galloway D, Bukits J, Ford G (2013) Bulletin of British Earthquakes 2012. British geological survey seismological report, OR/13/54, United Kingdom

Garcia-Moreno D, Verbeeck K, Camelbeeck T, De Batist M, Oggioni F, Zurita Hurtado O, Versteeg W, Jomard H, Collier JS, Gupta S, Trentesaux A, Vanneste K (2015) Fault activity in the epicentral area of the 1580 Dover Strait (Pas-de-Calais) earthquake (Northwestern Europe). Geophys J Int 201(2):528-542

Gerstenberger MC, Marzocchi W, Allen T, Pagani M, Adams J, Danciu L, Field EH, Fujiwara H, Luco N, Ma K-F, Meletti C, Petersen MD (2020) Probabilistic seismic hazard analysis at regional and national scales: state of the art and future challenges. Rev Geophys. https://doi.org/10.1029/2019RG000653

Gölke M, Coblentz D (1996) Origins of the European regional stress field. Tectonophysics 266(1-4):11-24

Goulet CA, Bozorgnia Y, KuehnN, Al Atik L, Youngs RR, Graves RW, Atkinson GM (2017) NGA-East ground-motion models for the U.S. geological survey national seismic hazard maps, PEER Report 2017/03, Pacific Earthquake Engineering Research Center, University of California, Berkeley, US

Grünthal G, Wahlström E, Stromeyer D (2009) The unified catalogue of earthquakes in central, northern, and northwestern Europe (CENEC)—updated and expanded to the last millennium. J Seismol 13:517-541

Grünthal G, Wahlström E, Stromeyer D, Bosse C, Cotton F, Bindi D (2018) The probabilistic seismic hazard assessment of Germany - version 2016, considering the range of epistemic uncertainties and aleatory variability. Bull Earthq Eng 16(10):4339-4395

Gutenberg B, Richter CF (1954) Seismicity of the Earth and associated phenomena. Princeton University Press, Princeton, New Jersey

Heidbach O, Rajabi M, Reiter K, Ziegler M, the WSM Team (2016) World stress map database release 2016. GFZ Data Services

Holschneider M, Zöller G, Hainzl S (2011) Estimation of the maximum possible magnitude in the framework of a doubly truncated Gutenberg-Richter model. Bull Seismol Soc Am 101(4):1649-1659

Holschneider M, Zöller G, Clements R, Schorlemmer D (2014) Can we test for the maximum possible earthquake magnitude? J Geophys Res Solid Earth Planets 119:2019-2028

Hough SE, Page M (2011) Toward a consistent model for strain accrual and release for the New Madrid Seismic Zone, central United States. J Geophys Res. https://doi.org/10.1029/2010JB007783

Johnston AC, Coppersmith KJ, Kanter LR, Cornell CA (1994) The earthquakes of stable continental regions. EPRI Report, Electric Power Research Institute, Palo Alto

Johnston AC (1996). Seismic moment assessment of earthquakes in stable continental regions-III. New Madrid 1811-1812, Charleston 1886 and Lisbon 1755. Geophys J Int 126(2):314-344.

Kale Ö, Akkar S (2013) A new procedure for selecting and ranking ground-motion prediction equations (GMPEs): the Euclidean distance-based ranking (EDR) method. Bull Seismol Soc Am 103(2A):1069-1084

Lambeck K (1993) Glacial rebound of the British-Isles-1. Preliminary model results. Geophys J Int 115(3):941-959

Lilwall RC (1976) Seismicity and seismic hazard in Britain. Inst Geol Sci 4:13

Luen B, Stark PB (2012) Poisson tests for declustered catalogues. Geophys J Int 189:691-700

Main ID, Irving D, Musson RMW, Reading A (1999) Constraints on the frequency-magnitude relation and maximum magnitudes in the UK from observed seismicity and glacio-isostatic recovery rates. Geophys J Int 137(2):535-550

Manchuel K, Traversa P, Baumont D, Cara M, Nayman E, Durouchoux C (2018) The French seismic CATalogue (FCAT-17). Bull Earthq Eng 16:2227-2251

McGuire RK (2004) Seismic hazard and risk analysis. Earthquake Engineering Research Institute, Oakland $\mathrm{CA}$

Meletti C, D'Amico V, Martinelli F (2009) Homogeneous determination of maximum magnitude. SHARE Deliv 3:3 
Miller AC, Rice TR (1983) Discrete approximations of probability distributions. Manag Sci 29(3):352-362

Mosca I, Sargeant S, Baptie B, Walker RT (2019) Integrating outcomes from probabilistic and deterministic seismic hazard analysis in the Tien Shan. Bull Seismol Soc Am 109(2):688-715

Mosca I, Sargeant S, Baptie B, Musson RMW, Pharaoh T (2020) National seismic hazard maps for the UK: 2020 update. British Geological Survey Open Report, OR/20/053, United Kingdom

Mosca I (2019) Comparing seismic hazard software: M3C versus OpenQuake. British Geological Survey Open Report, OR/19/038, United Kingdom

Muir-Wood R (2000) Deglaciation seismotectonics: a principal influence on intraplate seismogenesis at high latitudes. Quat Sci Rev 19(14-15):1399-1411

Musson RMW (2000) The use of Monte Carlo simulations for seismic hazard assessment in the UK. Ann Geophys 43:1-9

Musson RMW (2007) British earthquakes. Proc Geol Assoc 118:305-337

Musson RMW (2011) Activity rates for seismic sources. SHARE Deliverable 3:7b

Musson RMW (2012a) Interpreting intraplate tectonics for seismic hazard: a UK historical perspective. J Seismol 16:261-273

Musson RMW (2012b) The effect of magnitude uncertainty on earthquake activity rates. Bull Seismol Soc Am 102(6):2771-2775

Musson RMW (2012c) PSHA validated by quasi observational means. Seismol Res Lett 83:130-134

Musson RMW, Sargeant S (2007) Eurocode 8 seismic hazard zoning maps for the UK. British Geological Survey Report CR/07/125, United Kingdom

Musson RMW, Winter PW (1996) Seismic hazard of the UK. AEA Technology Report, AEA/CS/16422000/ ZJ745/005

Musson RMW (1994) A catalogue of British earthquakes. British Geological Survey Global Seismology Report WL/94/04, United Kingdom

Musson RWM (2015) What was the largest British earthquake? SECED 2015 conference: earthquake risk and engineering towards a resilient world, Cambridge, United Kingdom, 9-10 July 2015

Neilson G, Musson RMW, Burton PW (1984) Macroseismic reports on historical British earthquakes V: The South and South West of England. British Geological Survey Global Seismology Report, 231, United Kingdom

Ottermöller L, Baptie B, Smith NJP (2009) Source parameters for the 28 April 2007 Mw 4.0 earthquake in Folkestone, United Kingdom. Bull Seismol Soc Am 99(3):1853-1867

Pagani M, Monelli D, Weatherill G, Danciu L, Crowley H, Silva V, Henshaw P, Butler L, Nastasi M, Panzeri L et al (2014) Open-quake engine: an open hazard (and risk) software for the global earthquake model. Seismol Res Lett 85(3):692-702

Pezeshk S, Zandieh A, Tavakoli B (2011) Hybrid empirical ground-motion prediction equations for eastern North America using NGA models and updated seismological parameters. Bull Seismol Soc Am 101(4):1859-1870

Pezeshk S, Zandieh A, Campbell KW, Tavakoli B (2018) Ground-Motion Prediction Equations for Central and Eastern North America Using the Hybrid Empirical Method and NGA-West2 Empirical GroundMotion Models. Bull Seismol Soc Am 108(4):2278-2304

Pharaoh TC (2018) The Anglo-Brabant Massif: persistent but enigmatic palaeo-relief at the heart of Western Europe. Proc Geol Assoc 129(3):278-328

Pharaoh TC, Morris JH, Long CB, Ryan PD (1996). Tectonic Map of Britain, Ireland and adjacent areas, sheet 1, scale 1:1500000. British Geological Survey, United Kingdom

Reiter L (1990) Earthquake hazard analysis: issues and insights. Columbia University Press, New York

Rietbrock A, Strasser FO, Edwards B (2013) A stochastic earthquake ground motion prediction model for the United Kingdom. Bull Seismol Soc Am 103(1):57-77

Rietbrock A, Edwards B (2019) Update of the UK stochastic ground motion model using a decade of broadband data. SECED 2019 Conference: Earthquake Risk and Engineering towards a Resilient World, Greenwich, United Kingdom, 9-10 September 2019

Roberts NS, Bell AF, Main I (2015) Are volcanic seismic b-value high, and if so when? J Volcanol Geotherm Res 308:127-141

Sargeant SL, Stafford PJ, Lawley R, Weatherill G, Weston A-JS, Bommer JJ, Burton PW, Free M, Musson RMW, Kuuyor T, Rossetto T (2008) Observations from the Folkestone, UK, earthquake of 28 April 2007. Seismol Res Lett 79(5):672-687

Scherbaum F, Delavaud W, Riggelsen C (2009) Model selection in seismic hazard analysis: an informationtheoretic perspective. Bull Seismol Soc Am 99(6):3234-3247

Shennan I, Bradley S, Milne G, Brooks A, Bassett S, Hamilton S (2006) Relative sea-level changes, glacial isostatic modelling and ice-sheet reconstructions from the British Isles since the Last Glacial Maximum. J Quat Sci 21(6):585-599 
Stein S, Liu M, Camelbeeck T, Merino M, Landgraf A, Hintersberger E, Kuebler S (2015) Challenges in assessing seismic hazard in intraplate Europe. In: Landgraf A, Kuebler S, Hintersberger E, Stein S (Eds) Seismicity, Fault rupture and earthquake hazards in slowly deforming region. Geol Soc Spec Publ 432:29-32

Strasser FO, Abrahamson NA, Bommer JJ (2008) Truncation of the distribution of ground motion residuals. J Seismol 12:79-105

Tromans IJ, Aldama-Bustos G, Douglas J, Lessi-Cheimariou A, Hunt S, Davi M, Musson RMW, Garrard G, Strasser FO, Robertson C (2019) Probabilistic seismic hazard assessment for a new-build nuclear power plant site in the UK. Bull Earthq Eng 17(1):1-36

USNRC (2012) Practical implementation guidelines for SSHAC level 3 and 4 hazard studies, U.S. Nuclear Regulatory Commission, NUREG-2117, Rev. 1

Van Houtte C, Drouet S, Cotton F (2011) Analysis of the origins of $\kappa$ (Kappa) to compute hard rock to rock adjustment factors for GMPEs. Bull Seismol Soc Am 101(6):2926-2941

Villani M, Polidoro B, Ader T, McCully R, Lubkowski Z, Courtney T, Walsh M (2019) A selection of GMPEs for the UK based on ground motion and macroseismic datasets. Bull Seismol Soc Am 109(4):1378-1400

Villani M, Lubkowski Z, Free M, Musson RMW, Polidoro B, McCully R, Koskosidi A, Oakman C, Courtney T, Walsh M (2020) A probabilistic seismic hazard assessment for Wylfa Newydd, a new nuclear site in the United Kingdom. Bull Earthq Eng. https://doi.org/10.1007/s10518-020-00862-8

Wessel P, Luis JF, Uieda L, Scharroo R, Wobbe F, Smith WHF, Tian D (2019) The generic mapping tools version 6. Geochem Geophys Geosyst 20:5556-5564

Wheeler RL (2009) Methods of Mmax estimation east of the rocky mountains. U.S. Geological Survey Open-File Report 2009-1018

Wiemer S, Danciu L, Edwards B, Marti M, Fäh D, Hiemer S, Wössner J, Cauzzi C, Kästli P, Kremer K (2016) Seismic hazard model 2015 for Switzerland (SUIhaz2015). Swiss Seismological Service, Zurich, Switzerland

Wiemer S, Wyss M (2000) Minimum magnitude of complete reporting in earthquake catalogues: examples from Alaska, the Western United States, and Japan. Bull Seismol Soc Am 90:859-869

Wöessner J, Giardini D, The SHARE Consortium (2015) Seismic hazard estimates for the Euro-Mediterranean region: a community-based probabilistic seismic hazard assessment. Bull Earthq Eng 13:3553-3596

Wöessner J, Wiemer S (2005) Assessing the quality of earthquake catalogues: estimating the magnitude of completeness and its uncertainty. Bull Seismol Soc Am 95(2):684-698

Woodcock N, Strachan R (2012) Geological history of Britain and Ireland. Blackwell Publishing, Oxford

Yenier E, Atkinson GM (2015) Regionally adjustable generic ground-motion prediction equation based on equivalent point-source simulations: Application to central and eastern North America. Bull Seismol Soc Am 105:1898-2009

Zechar JD, Jordan TH (2010) Simple smoothed seismicity earthquake forecasts for Italy. Ann Geophys 53(3):99-105

Publisher's Note Springer Nature remains neutral with regard to jurisdictional claims in published maps and institutional affiliations. 